\title{
BCL-2 inhibition with ABT-737 prolongs survival in an NRAS/BCL-2 mouse model of AML by targeting primitive LSK and progenitor cells.
}

Link to publication record in Manchester Research Explorer

Citation for published version (APA):

Beurlet, S., Omidvar, N., Gorombei, P., Kreif, P., Le Pogam, C., Setterblad, N., de la Grange, P., Leboeuf, C., Janin, A., Noguera, M. E., Hervatin, F., Sarda-Mantel, L., Konopleva, M., Andreeff, M., Tu, A. W., Fan, A. C., Felsher, D. W., Whetton, A., Pla, M., ... Padua, R. A. (2013). BCL-2 inhibition with ABT-737 prolongs survival in an NRAS/BCL-2 mouse model of AML by targeting primitive LSK and progenitor cells. Blood, 122(16), 2864-2876.

\section{Published in:}

Blood

\section{Citing this paper}

Please note that where the full-text provided on Manchester Research Explorer is the Author Accepted Manuscript or Proof version this may differ from the final Published version. If citing, it is advised that you check and use the publisher's definitive version.

\section{General rights}

Copyright and moral rights for the publications made accessible in the Research Explorer are retained by the authors and/or other copyright owners and it is a condition of accessing publications that users recognise and abide by the legal requirements associated with these rights.

\section{Takedown policy}

If you believe that this document breaches copyright please refer to the University of Manchester's Takedown Procedures [http://man.ac.uk/04Y6Bo] or contact uml.scholarlycommunications@manchester.ac.uk providing relevant details, so we can investigate your claim.

\section{OPEN ACCESS}




\title{
BCL-2 inhibition with ABT-737 prolongs survival in an NRAS/BCL-2 mouse model of AML by targeting primitive LSK and progenitor cells
}

\author{
Stephanie Beurlet, ${ }^{1,2}$ Nader Omidvar, ${ }^{3}$ Petra Gorombei, ${ }^{1,2}$ Patricia Krief, ${ }^{1,2}$ Carole Le Pogam, ${ }^{1,2}$ Niclas Setterblad, ${ }^{2}$ \\ Pierre de la Grange, ${ }^{4}$ Christophe Leboeuf, ${ }^{2,5,6}$ Anne Janin, ${ }^{2,5,6}$ Maria-Elena Noguera, ${ }^{6}$ Florence Hervatin, ${ }^{7}$ \\ Laure Sarda-Mantel, ${ }^{2,8}$ Marina Konopleva, ${ }^{9}$ Michael Andreeff, ${ }^{9}$ Andrea W. Tu, ${ }^{10}$ Alice C. Fan, ${ }^{11}$ Dean W. Felsher, ${ }^{11}$ \\ Anthony Whetton, ${ }^{12}$ Marika Pla, ${ }^{1,2}$ Robert West, ${ }^{13}$ Pierre Fenaux, ${ }^{1,2,6}$ Christine Chomienne, ${ }^{1,2,6}$ and Rose Ann Padua ${ }^{1,2,6}$ \\ ${ }^{1}$ Institut National de la Santé et de la Recherche Médicale U940, Paris, France; ${ }^{2}$ Université Paris-Diderot, Sorbonne Paris Cité, Institut Universitaire \\ d'Hématologie, Unité Mixe de Recherche de Santé 940, Unité Mixe de Recherche de Santé 728, Paris, France; ${ }^{3}$ Haematology Department, Cardiff \\ University School of Medicine, Cardiff, United Kingdom; ${ }^{4}$ GenoSplice Technology, Institut Universitaire d'Hématologie, Paris, France; ${ }^{5}$ Institut National de la \\ Santé et de la Recherche Médicale U728, Paris, France; ${ }^{6}$ Assistance Publique-Hôpitaux de Paris, Hôpital Saint-Louis, Paris, France; ${ }^{7}$ Commissariat à \\ l'Energie Atomique, Service Hospitalier Frédéric Joliot, Orsay, France; ${ }^{8}$ Institut National de la Santé et de la Recherche Médicale U773, Université \\ Paris-Diderot, Sorbonne Paris Cité, Assistance Publique-Hôpitaux de Paris Hôpital Bichat, Paris, France; ${ }^{9}$ The University of Texas, MD Anderson Cancer \\ Center, Houston, TX; ${ }^{10}$ ProteinSimple, Santa Clara, CA; ${ }^{11}$ Stanford University Cancer Center, Stanford, CA; ${ }^{12}$ School of Cancer and Enabling Science, \\ University of Manchester, Manchester, United Kingdom; and ${ }^{13}$ Public Health, Cardiff University School of Medicine, Cardiff, United Kingdom
}

\section{Key Points}

- BCL-2 homology domain 3 mimetic inhibitor ABT-737 targets leukemia initiating cells and progenitors.

- Dephosphorylates RAS signaling proteins and regulates proliferation and differentiation genes detected by gene expression profiling.

Myelodysplastic syndrome (MDS) transforms into an acute myelogenous leukemia (AML) with associated increased bone marrow (BM) blast infiltration. Using a transgenic mouse model, MRP8[NRASD12/hBCL-2], in which the NRAS:BCL-2 complex at the mitochondria induces MDS progressing to AML with dysplastic features, we studied the therapeutic potential of a BCL-2 homology domain 3 mimetic inhibitor, ABT-737. Treatment significantly extended lifespan, increased survival of lethally irradiated secondary recipients transplanted with cells from treated mice compared with cells from untreated mice, with a reduction of BM blasts, Lin-/Sca- $1^{+} / \mathrm{c}-\mathrm{Kit}^{+}$, and progenitor populations by increased apoptosis of infiltrating blasts of diseased mice assessed in vivo by technicium-labeled annexin $V$ single photon emission computed tomography and ex vivo by annexin V/7-amino actinomycin D flow cytometry, terminal deoxynucleotidyltransferase-mediated dUTP nick end labeling, caspase 3 cleavage, and re-localization of the NRAS:BCL-2 complex from mitochondria to plasma membrane.
tion of wild-type (WT) AKT or protein kinase B, extracellular signal-regulated kinase $1 / 2$ and Phosphoprotein analysis showed restoration of wild-type (WT) AKT or protein kinase B, extracellular signal-regulated kinase $1 / 2$ and
mitogen-activated protein kinase patterns in spleen cells after treatment, which showed reduced mitochondrial membrane potential. Exon specific gene expression profiling corroborates the reduction of leukemic cells, with an increase in expression of genes coding for stem cell development and maintenance, myeloid differentiation, and apoptosis. Myelodysplastic features persist underscoring targeting of BCL-2-mediated effects on MDS-AML transformation and survival of leukemic cells. (Blood. 2013; 122(16):2864-2876)

\section{Introduction}

Myelodysplastic syndromes (MDS) are clonal stem cell hematologic disorders evolving to acute myelogenous leukemia (AML) and models multi-step leukemogenesis. The prognosis of patients who transform is poor and there are no efficient therapeutic strategies available for this largely elderly population. Activating neuroblastoma-Rasheed sarcoma virus cellular homologue $(N-R A S)$ mutations have been associated with poor prognosis in MDS patients and increased risk of progression to AML. ${ }^{1}$ We used an NRASD12 mouse ${ }^{2,3}$ and overexpression of human B cell lymphoma 2 (hBCL-2) ${ }^{4}$ to study MDS-AML progression.
The BCL-2 family of apoptotic regulators contains proteins that have at least $1 \mathrm{BCL}-2$ homology domain $3 .^{5}$ Apoptosis plays a key role in the physiopathology of MDS. Apoptosis of bone marrow (BM) hematopoietic cells has been shown in MDS and correlates with activation of apoptosis-related proteins. ${ }^{6}$ Decrease of apoptosis may also explain the clinical disease progression and accumulation of immature progenitor cells, correlating with a decrease of the BCL-2 associated protein X (BAX):BCL-2 ratio. ${ }^{7}$ Fifty percent of AML have increased BCL-2 expression, which correlates with poor prognosis. 8,9
Submitted July 24, 2012; accepted June 21, 2013. Prepublished online as Blood First Edition paper, August 13, 2013; DOI 10.1182/blood-2012-07445635.

S.B. and N.O. contributed equally to this study.

The online version of this article contains a data supplement.
The publication costs of this article were defrayed in part by page charge payment. Therefore, and solely to indicate this fact, this article is hereby marked "advertisement" in accordance with 18 USC section 1734. 
Using mutant- $N R A S^{2}$ and $\mathrm{h} B C L-2^{4}$ transgenes, we created a mouse model of AML. ${ }^{3}$ The BM, spleen, and liver of NRASD12/ hBCL-2 mice are infiltrated by myeloblasts associated with dysplastic features. The liver infiltration evaluated by terminal deoxynucleotidyltransferase-mediated dUTP nick end labeling (TUNEL) is anti-apoptotic, as expected by the overexpression of hBCL-2 in these cells. The Lin-/Sca- $1^{+} / \mathrm{c}-\mathrm{Kit}^{+}$(LSK) primitive compartment of marrow cells is expanded, correlating with an increase in myeloid progenitors. An activated RAS-guanosine triphosphate (GTP) and BCL-2 complex was noted in both $\mathrm{Macl}^{+}$ and Sca- $1^{+}$cells of the double transgenic mice and was absent in the $\mathrm{Sca}^{+}{ }^{+}$compartment of the single NRASD12 and BCL-2 transgenic mice. ${ }^{3}$ In the $\mathrm{Macl}^{+}$compartment, single BCL-2 recruits endogenous RAS to activate it. ${ }^{3}$ This complex is also observed in MDS patients correlating with the World Health Organization classification and percentage of BM blasts. ${ }^{10}$

ABT-737 is a small molecule able to bind the hydrophobic pocket of BCL-2, B cell lymphoma X protein (BCL-X), and BCL-w with a very high affinity, but with a low affinity for myeloid cell leukemia (MCL-1) and BCL-2 related fetal liver homologous murine A1. This binding prevents BCL-2 from blocking the formation of the BAX/BCL-2 homologous antagonist killer complex at the mitochondria and has been shown to effectively alter mitochondrial membrane potential (MMP). ${ }^{11}$ The efficacy of ABT-737 has already shown in vitro inducing apoptosis of carcinoma and AML cell lines, ${ }^{12}$ ex vivo on patients' blasts, ${ }^{11}$ in vivo on a mouse model of lymphoma ${ }^{13}$ and on a xenograft model of small cell lung cancer. ${ }^{14}$ The combination of ABT-737 with chemotherapeutic agents ${ }^{15-17}$ or other targeted therapy molecules ${ }^{18,19}$ has synergistic efficacy. A related orally bioavailable derivative, ABT-263 (Navitoclax) has been tested in a phase I clinical trial on patients with both small cell lung cancer and other solid tumors ${ }^{20,21}$ and chronic lymphocytic leukemia $^{22,23}$ in which acceptable toxicity and promising efficacy has been reported. Here we report on a preclinical study with ABT-737 in an AML mouse model.

\section{Methods}

\section{Transgenic mice}

The MRP8[NRASD12/hBCL-2] mice were generated from crosses of MRP8hBCL-2 with MRP8NRASD12 hemizygote mice in Friend leukemia Virus B strain from the National Institutes of Health $(\mathrm{FVB} / \mathrm{N})$, as previously described. $^{2-4}$ Mice were classified according to the Bethesda method ${ }^{24}$ as myeloid leukemia without maturation and will be referred to here as AML. Mice were maintained in the barrier facilities of the Institut Universitaire d'Hématologie, Paris, Hôpital Saint Louis, under the appropriate animal project licenses. All procedures complied with national regulations on the use of animals for experimentation. Mice were sacrificed based on veterinary advice or when they were moribund. The mice were bred and genotyped using standard husbandry and polymerase chain reaction techniques as described. ${ }^{3}$ These mice have some myeloid dysplasia in the BM, $60 \%$ to $90 \%$ of blasts, pancytopenia, and weight loss as we previously described ${ }^{3}$ (Figures 1A and 2B; supplemental Figure 1). Two-week-old pups were euthanized to identify a pre-leukemic phase of the disease.

\section{ABT-737}

ABT-737 was available either as a stock solution at $200 \mathrm{mg} / \mathrm{mL}$ in dimethylsulfoxide or as a powder (kindly provided and synthesized by MD Anderson Cancer Center or as a generous gift by Abbott Laboratories, Green Oaks, IL); both preparations were equally active. The final formulation was $30 \%$ propylene glycol, $5 \%$ Tween $80,65 \%$ double distilled water, $\mathrm{pH} 4-$
$5.75 \mathrm{mg} / \mathrm{kg}$ and was administered 3 times per week (15 injections for 33 days) unless otherwise indicated (Figure 1B).

\section{Tissue and cell preparation}

The BM and spleen were prepared as previously described and detailed in the supplemental Methods. ${ }^{3}$

\section{Secondary transplantation}

Spleen cells $\left(10^{7}\right)$ from untreated and treated mice were injected intravenously into lethally irradiated $(2 \times 5$ gray) syngeneic FVB/N mice. Three weeks after transplant hBCL-2 expression was measured by flow cytometry.

\section{Progenitor colony assay}

Colony assays were performed using the Methocult media, as recommended by the manufacturer (Stem Cell Technologies, Vancouver, BC, Canada) detailed in the supplemental Methods.

\section{Immunofluorescence and confocal microscopy}

Immunofluorescence and microscopy was undertaken, as we had previously described $^{10}$; detailed in the supplemental Data.

\section{Flow cytometric apoptosis assessment:annexin/V- 7AAD}

Apoptosis was assessed using annexinV/7-amino actinomycin D (7AAD) staining and flow cytometry, as detailed in the supplemental Data. ${ }^{25}$

\section{MMP}

MMP was measured using $\mathrm{DiOC}_{2}$ (3) (Invitrogen, Carlsad, CA), as detailed in the supplemental data. Background corrected mean fluorescence intensity using unstained cells was used to calculate the FL3/FL1 ratios of $\mathrm{DiOC}_{2}(3)$ test samples, as previously described. ${ }^{26}$

\section{Single photon emission computed tomography (SPECT)}

ANX-labeling. Technicium $\left({ }^{99 \mathrm{~m}} \mathrm{Tc}\right)$-Annexin-V (ANX), which allows noninvasive in vivo detection of apoptosis, was prepared by injecting sodium pertechnetate $\left(400 \pm 20\right.$ mega becquerel drawn-up from a ${ }^{99 \mathrm{~m}} \mathrm{Tc}$ generator, freshly eluted) with stannous Tricine in a sterile vial containing annexin V (Theseus Imaging Corp., Cambridge, United Kingdom). After shaking, the preparation was left to stand 15 minutes at room temperature. The quality control was performed with instant thin-layer chromatography, using citric acid/dextrose solution as eluant. The radiolabeling yield was always greater than $88 \%$. ANX-scintigraphy imaging is detailed in the supplemental Data.

\section{TUNEL}

Apoptosis was assessed by in situ detection of fragmented DNA using the TUNEL assay on $5-\mu \mathrm{m}$ paraffin embedded liver sections as detailed in the supplemental Data. ${ }^{3}$

\section{RAS activation assays and western blot analysis}

RAS pull down assays and western blots were undertaken as detailed in the supplemental Data. For in vitro assays, AML spleen cells were isolated and cultured in the presence of 10, 100, or $500 \mathrm{nM}$ of ABT-737 dissolved in dimethylsulfoxide and diluted in culture media for 24 hours. Western blot analysis was undertaken to determine the phosphorylation states of RAS signaling proteins extracellular signal-regulated kinase (ERK) and murine thymoma viral oncogene homologue 1 isolated from the ak mouse strain (AKT) as detailed in the supplemental Data.

\section{NanoPro assay}

Splenocyte cells $\left(10^{6}\right)$ isolated from transgenic mice were lysed in radio immunoprecipitation assay buffer and subjected to a nanofluidic proteomic 
A

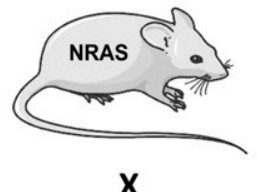

$\mathbf{X}$
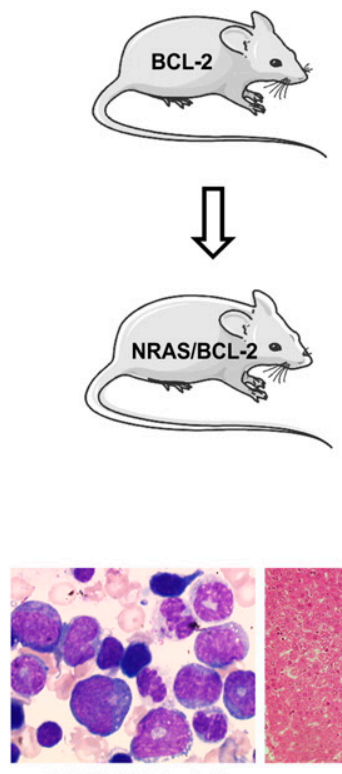

BM $(8 \%$ blasts)

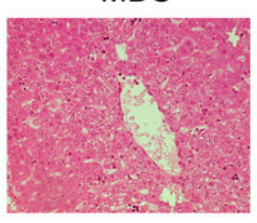

Liver

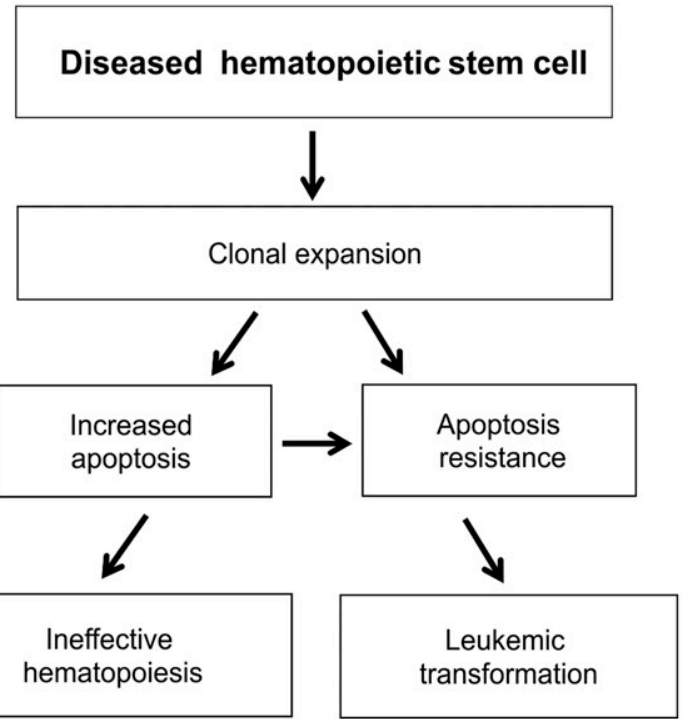

MRP8[BCL-2/NRASD12]

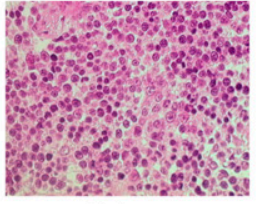

Spleen

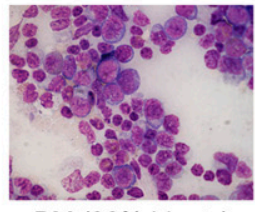

BM $(90 \%$ blasts)

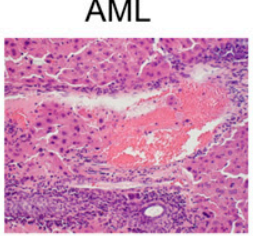

Liver
Human Multi-step

Pathophysiology

\section{2-weeks old}

4-weeks old

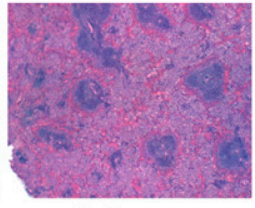

Spleen

B
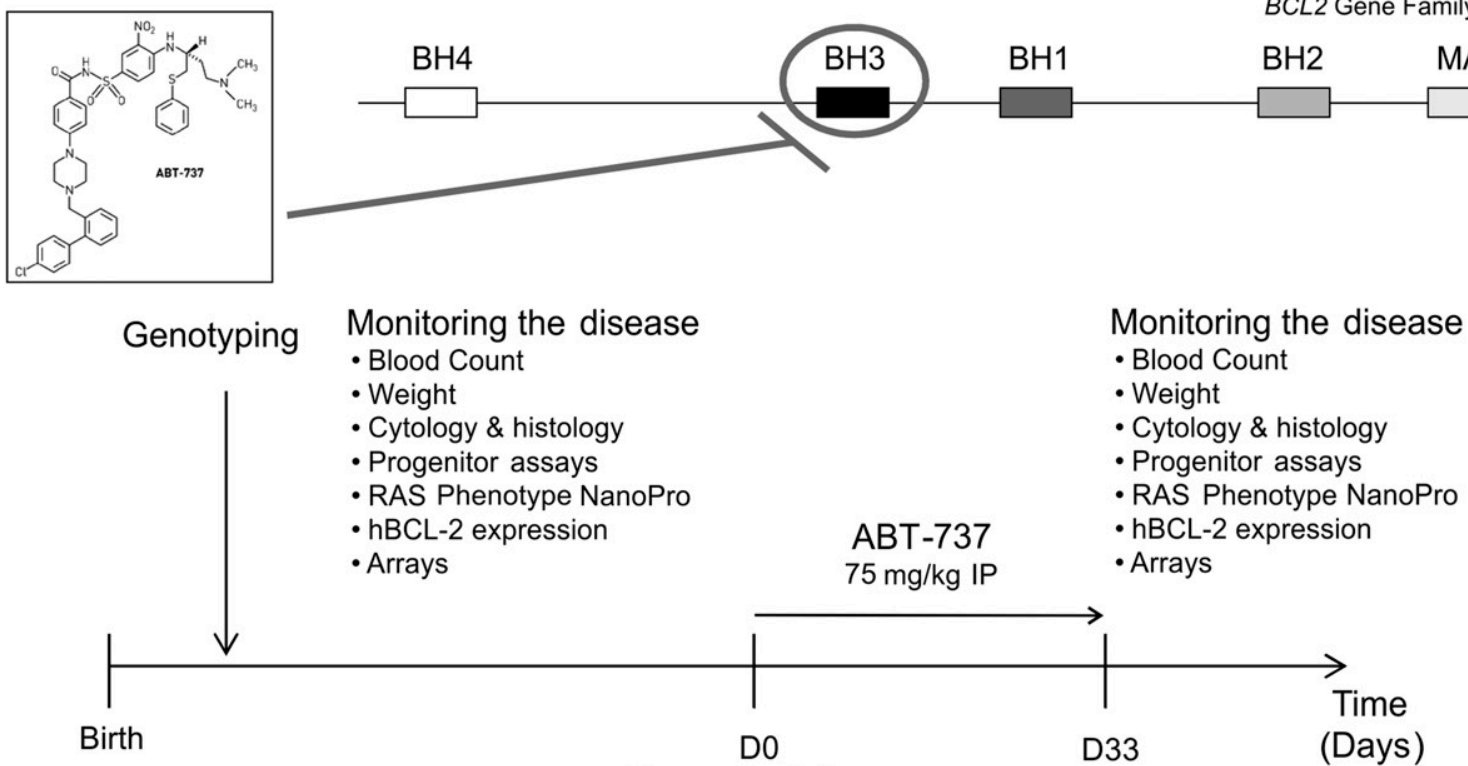

Birth

BCL2 Gene Family

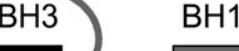

$\mathrm{BH} 2$

MA

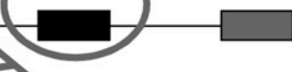

Diagnosis of disease confirmed hBCL-2

reduced weight blood count anormal

Figure 1. The model and protocol. (A) Schematic of the multistep process of leukemogenesis and derivation of the animal models of NRASD12 and hBCL-2-mediated MDS and AML. (B) ABT-737 treatment protocol. MA, membrane anchor.

immunoassay (NIA) run on the NanoPro1000 27 (ProteinSimple, Santa Clara, CA) mixing $0.1 \mathrm{mg} / \mathrm{mL}$ of lysate in a final volume of $15 \mu \mathrm{L}$ loaded in a 384-well plate with 5 to 8 gradient ampholyte mix. Antibodies were diluted in ProteinSimple antibody diluent: mitogen-activated protein kinase (MEK)1 (Upstate 07-641; Millipore, Billerica, MA) 1:100, MEK2 (Cell Signaling Technology, MA). Samples were run in triplicate. 
A
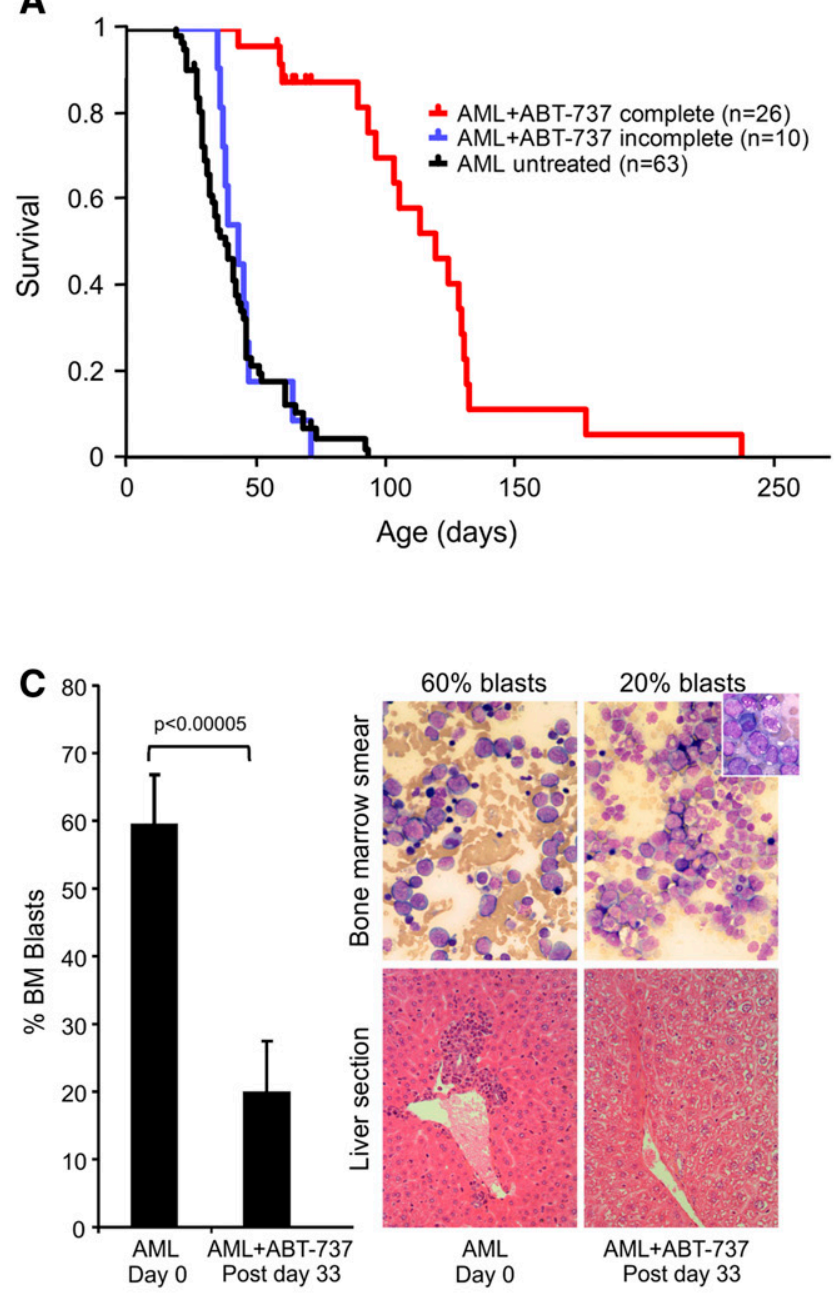

$20 \%$ blasts

E

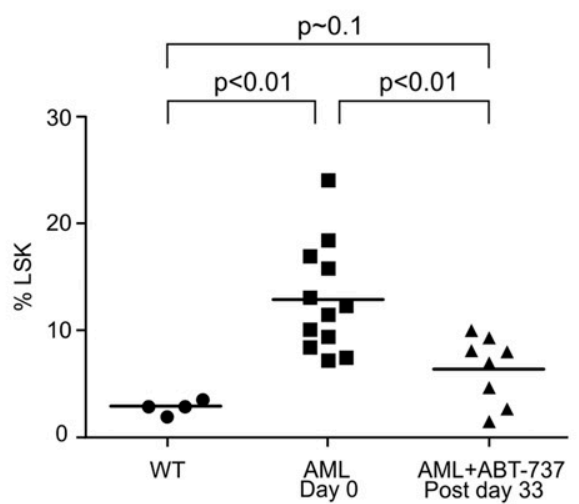

B

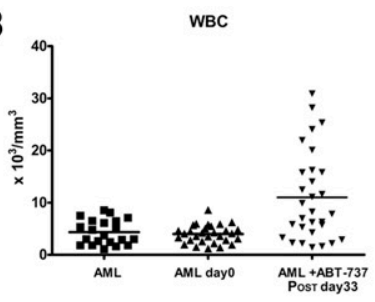

Lymphocytes

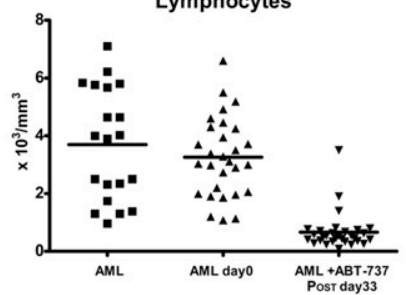

D

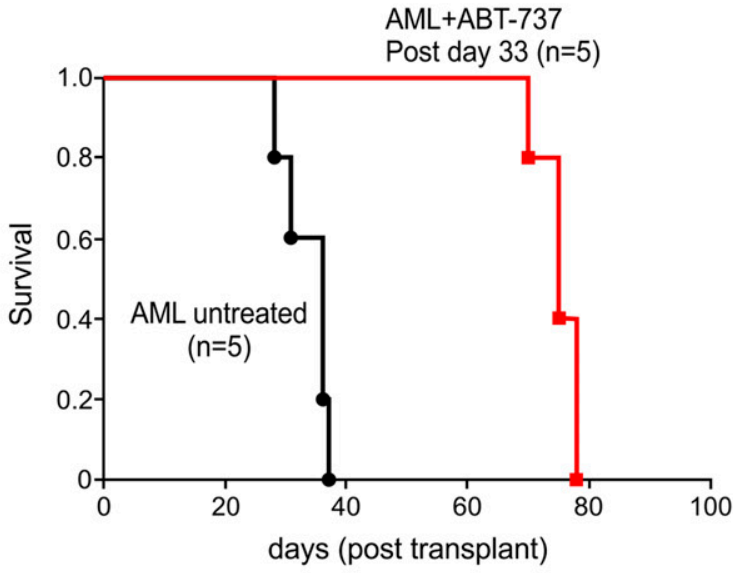

$\mathbf{F}$

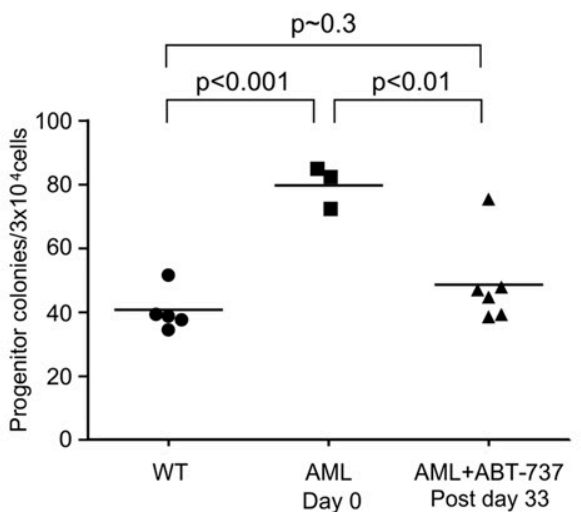

Figure 2. ABT-737 rescues clinical features of AML mice. (A) Kaplan-Meier survival curves showing prolonged survival of $A M L$ mice who completed treatment with ABT-737 ( $n=26$, red line), mice who failed to complete treatment $(\mathrm{n}=10$, blue line), and untreated mice $(\mathrm{n}=63$, black line) plotted from date of birth $(P<.0001)$. (B) White blood cell counts (WBC) (pretreatment vs posttreatment, $P<.0001$ ), neutrophil counts (pretreatment vs posttreatment, $P<.05$ ), lymphocytes (pretreatment vs posttreatment, $P<.0001$ ), and platelet counts (PLT) (pretreatment vs posttreatment, $P<.0001$ ) are shown (mean \pm standard deviation, $\mathrm{n}=30$ mice in the pretreatment and posttreatment groups; $\mathrm{n}=31$ in the untreated group). There were no significant differences between untreated and pretreatment AML groups. (C) Percentage AML BM blasts pretreatment and posttreatment after day 33 from start of treatment $(n=6$ mice). Giemsa stained BM smears showing decreased marrow blasts after treatment (shown in low power [LP $\times 50$ magnification]) and hematoxylin and eosin stained liver sections with infiltration in the untreated mice and clearance in the treated mice postday 33 . Representatives of 3 mice: (D) differential survival of mice transplanted each with $10^{7}$ spleen cells from AML untreated (black) or treated (red) mice into lethally irradiated FVB/N recipients ( $\mathrm{n}=5$ in each group) $\left(\log -\right.$ rank $\left.\chi^{2}=9.496 ; P<.005\right)$. (E) Significant reduction in the Lin-/Sca-1 ${ }^{+} / \mathrm{c}-\mathrm{Kit}^{+}(\mathrm{LSK})$ population of untreated $(\mathrm{n}=12)$ and treated $(\mathrm{n}=8)(P<.01)$; untreated mice analyzed compared with WT FVB/N mice $(P<.01)$; treated compared with WT mice $(\mathrm{n}=6)(P \sim .1)$. (F) ABT-737 targets myeloid progenitors. Dot plots showing numbers of day 7 colony-forming unit-granulocyte macrophage per $3 \times 10^{4}$ cells plated per dish from BMs of diseased untreated and normal mice $(P<.001)$; untreated compared with treated mice were statistically different $(P<.01)$ (mean \pm standard deviation of $n=4$ mice analyzed postday 33). There was no statistical difference between the WT and post-ABT-737 treatment groups $(P \sim$.3). 
Table 1. Target genes regulated after ABT-737 treatment of AML mice

\begin{tabular}{lcccc}
\hline Gene symbol & Regulation & Fold change & P value & Entrez gene ID \\
\hline Proliferation related genes downregulated & & & \\
\hline Myc & Down & 2.08 & $3.89 \mathrm{E}-02$ & 17869 \\
\hline Mcm5 & Down & 1.64 & $2.31 \mathrm{E}-02$ & 17218 \\
\hline Mcm7 & Down & 1.53 & $4.95 \mathrm{E}-02$ & 17220 \\
\hline E2f1 & Down & 1.52 & $3.06 \mathrm{E}-02$ & 13555 \\
\hline Pole4 & Down & 1.65 & $1.36 \mathrm{E}-02$ & 66979 \\
\hline Myeloid differentiation genes & upregulated & & \\
\hline Csf1 & Up & 1.80 & $2.24 \mathrm{E}-02$ & 12977 \\
\hline Cd14 & Up & 2.08 & $2.81 \mathrm{E}-02$ & 12475 \\
\hline Csf3r & Up & 3.36 & $2.40 \mathrm{E}-02$ & 12986 \\
\hline Itgb2 & Up & 1.89 & $2.33 \mathrm{E}-02$ & 16414 \\
\hline Itgb2l & Up & 3.51 & $3.55 \mathrm{E}-02$ & 16415 \\
\hline Rara & Up & 1.56 & $9.60 \mathrm{E}-03$ & 19401 \\
\hline Apoptosis related genes upregulated & & \\
\hline Tnfrsf23 & Up & 5.22 & $2.20 \mathrm{E}-03$ & 79201 \\
\hline Mapk13 & Up & 3.10 & $3.00 \mathrm{E}-02$ & 26415 \\
\hline Tnfrsf17 & Up & 2.17 & $3.66 \mathrm{E}-02$ & 21935 \\
\hline Card10 & Up & 1.67 & $3.17 \mathrm{E}-02$ & 105844 \\
\hline Ctsd & Up & 1.72 & $2.16 \mathrm{E}-02$ & 13033 \\
\hline Dapk2 & Up & 1.63 & $3.07 \mathrm{E}-02$ & 13143 \\
\hline Capn2 & Up & 1.62 & $4.03 \mathrm{E}-02$ & 12334 \\
\hline Dapk1 & Up & 1.54 & $3.06 \mathrm{E}-02$ & 69635 \\
\hline Nfkbiz & Up & 1.53 & $6.20 \mathrm{E}-03$ & 80859 \\
\hline Cox4i2 & Up & 1.53 & $2.12 \mathrm{E}-02$ & 84682 \\
\hline Parp4 & Up & 1.51 & $1.78 \mathrm{E}-03$ & 328417 \\
\hline Stem cells related upregulated & & & 21416 \\
\hline Tcf7l2 & Up & 2.13 & $3.38 \mathrm{E}-02$ & 57746 \\
\hline Piwil2 & Up & 2.20 & $3.06 \mathrm{E}-02$ & 12166 \\
\hline Bmpr1a & Up & 2.31 & $4.63 \mathrm{E}-02$ & 20750 \\
\hline Spp1 & 4.32 & $1.38 \mathrm{E}-0.2$ & \\
\hline
\end{tabular}

Fold change of treated compared with untreated mice was considered significant when $\geq 1.5$ and $P$ value $\leq .05$. The arrays were normalized to $F V B / N$, and then the treated was compared with the untreated group $(n=3)$ (GEO accession no. GSE48601)

\section{Cell preparation and RNA extraction}

Spleen cells were labeled with anti-Sca- $1^{+}$antibodies coupled with microbeads from Miltenyi and were then sorted using an AutoMacs separator (Miltenyi Biotec, Bergisch Gladbach, Germany). The $5 \times 10^{6}$ to $10^{7} \mathrm{Sca}-1^{+}$sorted cells were used to extract total RNA using TRIzol (Invitrogen, CA). Quantification and quality of the RNAs were assessed using a Nanodrop (Thermoscientific).

\section{Affymetrix exon array hybridization}

Affymetrix Mouse Exon 1.0 ST arrays were hybridized by GenoSplice technology (www.genosplice.com), according to the Ambion WT protocol (Life Technologies, Saint Aubin, France) and Affymetrix (Santa Clara, CA) labeling and hybridization recommendations as detailed in the supplemental Data.

\section{Array data and statistical analysis}

Affymetrix Mouse Exon 1.0 ST Array dataset analysis and visualization were made using EASANA (GenoSplice Technology), which is based on the GenoSplice's FAST DB annotations, as detailed in the supplemental Data. ${ }^{28}$ Exon Array data were normalized using quantile normalization. Background correction was made by using the antigenomic probes and probe selection was made as previously described. ${ }^{29}$ Genes were considered significantly regulated when fold change was $\geqslant 1.5$ and $P$ value $\leqslant .05$ when untreated and treated samples were compared. The values of the AML untreated or treated arrays were normalized to FVB/N and then compared with each other (Table 1; supplemental Table 1).

\section{Statistics}

Survival of treated mice was compared with untreated controls by using the Kaplan Meier method with log-rank test of significance. Some AML mice were euthanized according to veterinary advice (at the end of treatment) due to disease; all of these mice were shown to have advanced disease at necropsy. The combined end point (died naturally or euthanized due to advanced disease) of untreated and treated mice was used for comparison. Further analysis compared only those that received the full course of treatment with controls to test "biological effectiveness."

Blood counts, LSK, progenitor, apoptosis, and MMP assays were presented as the mean \pm standard deviation, and between group differences as the mean difference (95\% confidence interval of difference). The unpaired Student $t$ test was also used.

\section{Results}

\section{Identification of preleukemia}

The MRP8[NRASD12/hBCL-2] mice developed AML with dysplastic features in approximately 21 to 27 days $^{3}$ (Figure 1A). Some degree of dysplasia was noted and some mice had pancytopenia at about day 27 correlating with expression of BCL2 in $40 \%$ cells. ${ }^{3}$ Two-week-old double transgenic NRASD12/hBCL-2 mice showed reduced $\mathrm{BM}$ blasts $(5 \%$ to $8 \%[\mathrm{n}=3]$ ) with dysplasia compared with $60 \%$ to $90 \%$ in the 4 -week-old AML mice ${ }^{3}$ with absence of tissue invasion, whereas the adult mice have extensive tissue invasion and evidence of extramedullary hematopoiesis (Figure 1A). Late apoptosis measured by annexin $\mathrm{V}^{+} / 7 \mathrm{AAD}^{+}$of the $\mathrm{BM}$ shows increased apoptosis in these 2-week-old mice compared with wild-type (WT) and BCL-2 mice (data not shown). These young mice may be considered as the preleukemic or MDS stage.

\section{ABT-737 treatment prolongs survival in AML transgenic mice}

Median survival has been noted to be approximately 40 days with all mice dying by 90 days compared with median survival in treated mice of 97 days with mice living up to 235 days (supplemental Figure 2). Treatment was initiated at about 3 to 4 weeks after birth, after confirmation of genotype and expression of hBCL-2 by flow cytometry in 36 mice, which were compared with 63 untreated diseased mice. Five of 36 (14\%) ABT-737-treated and 24 of 63 (38\%) untreated diseased mice were euthanized, according to veterinary recommendations. When comparing the combined end point (died naturally or euthanized due to advanced disease), the survival difference between treated and untreated was highly significant ( $\left.\log \operatorname{rank} \chi^{2}=40.1 ; P<.0001\right)$ (supplemental Figure 2 ). Ten mice died before completion of treatment and 26 mice received the full 15 injections of ABT-737. This subset of 26 of the 36 treated mice that received full courses of treatment was analyzed separately (median survival, 114 days) and was shown to be significantly different from both the untreated controls or noncompleters $\left(P<.0001 ; \chi^{2}=51.8\right.$ and $\chi^{2}=38.2$ compared with controls or noncompleters, respectively) (Figure $2 \mathrm{~A}$ ), underscoring drug efficacy and tolerance. There was no significant difference between noncompleters $(\mathrm{n}=10)$ and untreated mice. Significant improvement was also seen in mouse overall clinical presentation, weight gain, and behavior (supplemental Figure 1). The ABT-737-treated mice had some improvement in peripheral blood parameters with increased peripheral blood neutrophils, increased white blood cells compared with pretreatment and untreated counts, which were identical, illustrating that the 2 groups were 
A

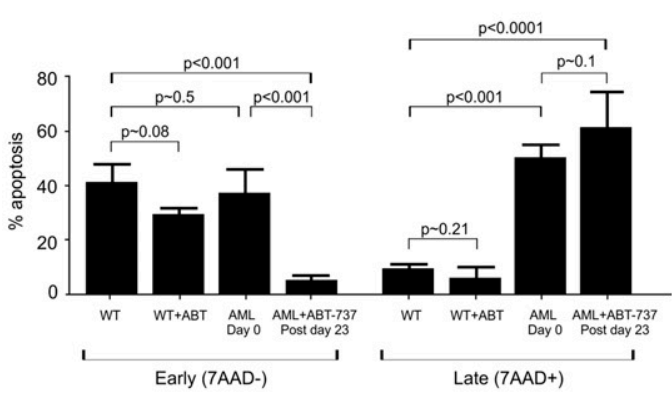

C
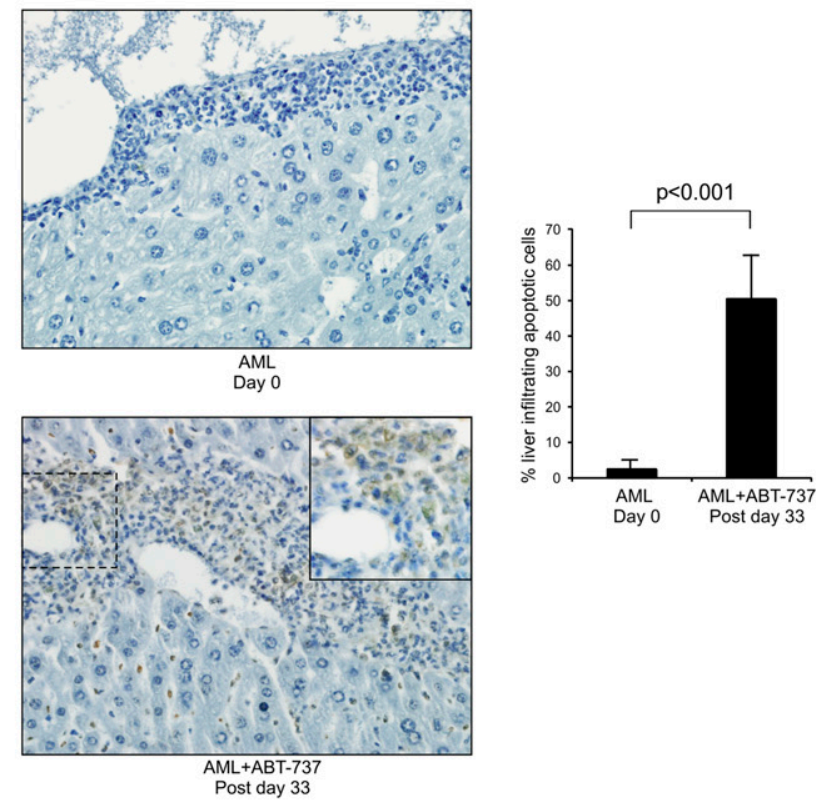

D

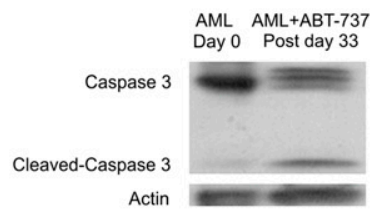

B
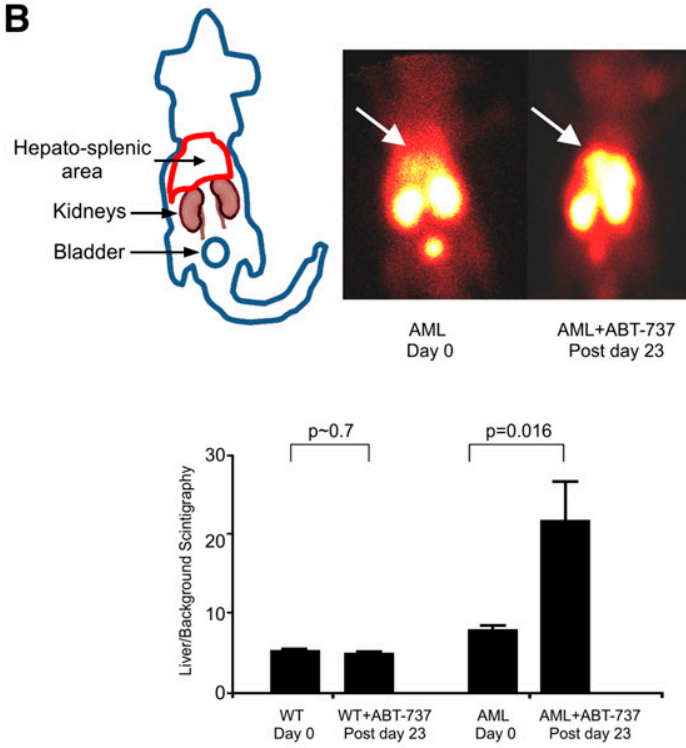

E

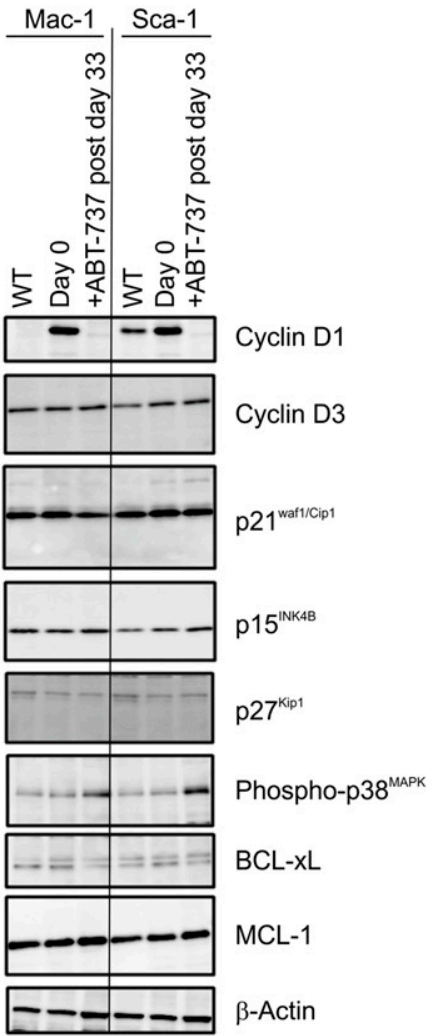

Figure 3. ABT-737 treatment-induced apoptosis of AML cells in the liver and the spleen of the mice, despite persistence of BCL-2 in the RAS-GTP complex and relocalization of the RAS:BCL-2 complex. (A) Histogram of mean \pm standard deviation (SD) showing an increase of late/necrotic apoptotic cells $(n=3)$. (B) Paired untreated and treated radioisotope heat maps of ${ }^{99 \mathrm{~m}} \mathrm{Tc}$ labeled annexin- $\mathrm{V}$, which targets apoptotic cells and is metabolized in the kidney and bladder, shows greater intensity around the location of the liver in the pretreated AML mouse (day $0, n=6$ ), which is increased after day 23 (postday 23 ) after 10 injections. Histogram of mean \pm SD showing an increase of apoptotic cells in AML mice after treatment $(n=5$ mice), whereas WT mice do not show a significant increase in uptake of the label (WT, $n=14$ untreated and $n=3$ treated). (C) Representative DNA fragmentation as demonstrated by TUNEL-positive myeloid cells is significantly greater (postday 33 ) in the liver of mice; histogram of untreated and treated AML mice (mean \pm SD of $n=4$ ). (D) Representative western blot of spleen cells of AML mice probed with anti-caspase 3 antibody showing untreated (day 0 ) and caspase 3-mediated cleavage after treatment (postday 33) with reprobing with anti-ßactin antibody showing protein loading. Results are representative of 3 mice. (E) Representative western blot of protein lysates from Mac- $1^{+}$and Sca- $1^{+}$enriched spleen cells of normal WT, AML untreated (day 0), and ABT-737 treated (postday 33) mice immunoprobed with cyclin D1 and D3, p2 $1^{\text {Waf1/Cip1 }}$, p1 $5^{\text {INK4B }}$, p2 $7^{\text {Kip1 }}$, phospho-p38 ${ }^{\mathrm{MAPK}}$, BCL-xL, MCL-1, and $\beta$-actin (control for loading) $(\mathrm{n}=2$ mice) .

similar (Figure 2B), whereas lymphopenia and thrombocytopenia persisted (Figure 2B); toxicity of ABT-737 on platelets in mice and humans is well known. ${ }^{30} \mathrm{~A}$ significant reduction in BM blast counts
$(19 \% \pm 7 \%$ vs $60 \% \pm 6 \%$ in treated vs untreated mice), with a reduced to complete clearance of blast invasion of the spleen and liver was observed (Figure 2C). Secondary transplants of lethally 
A
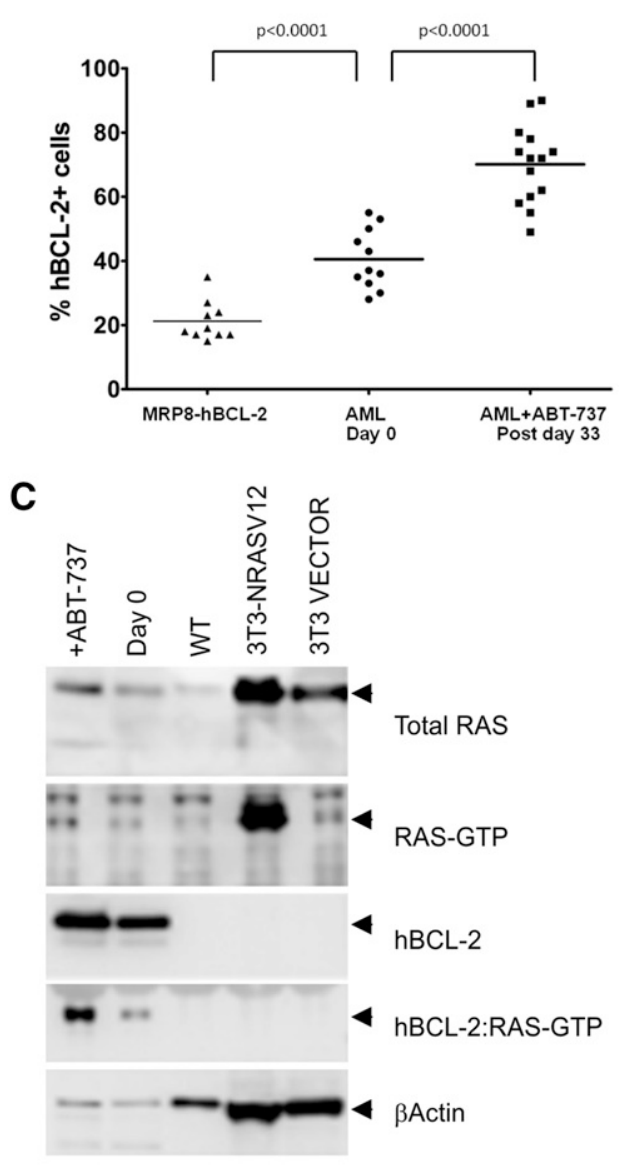

B
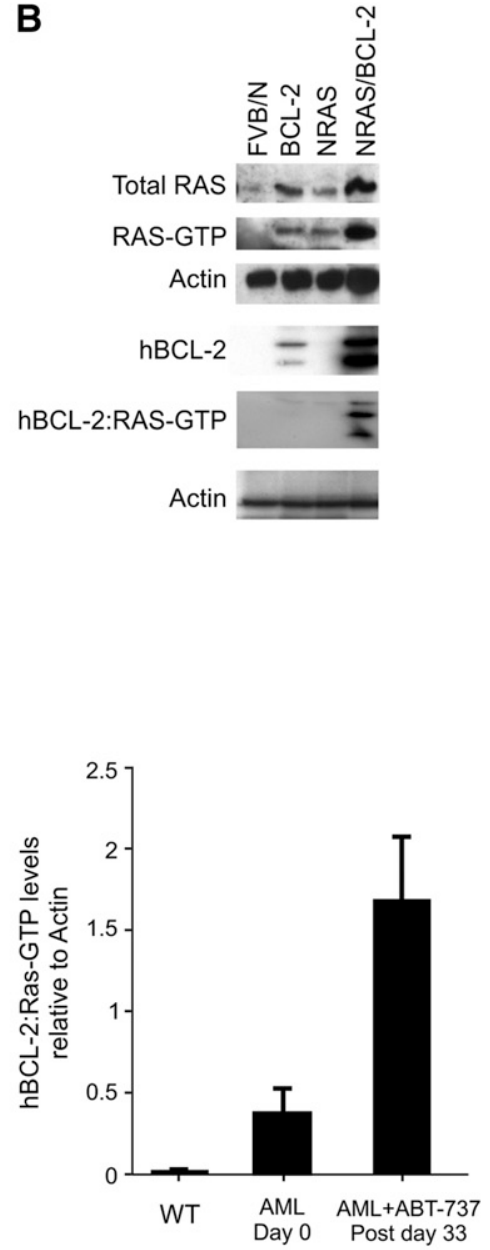

Total RAS

RAS-GTP

Actin

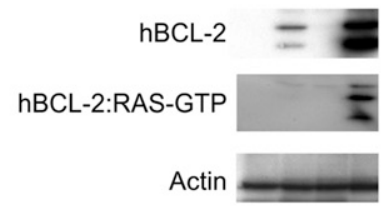

P-hBCL-2

Threonine 56

P-hBCL-2

Serine 70

hBCL-2 TOT

Actin

\section{E}

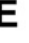

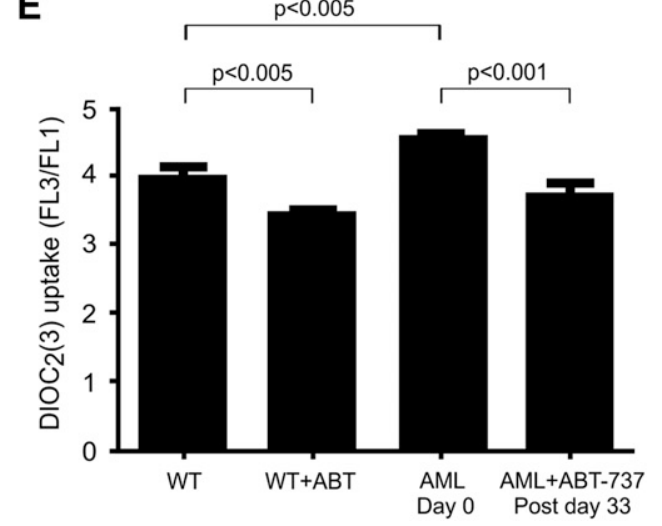

Figure 4. RAS and BCL-2 status of AML mice. (A) Percentage of peripheral blood BCL-2-positive cells in 4-week-old single transgenic $(n=10)$, untreated at 4-weeks old (day $0, n=11$ ), and posttreatment mice (postday $33, n=14$ ) showing a significant increase in BCL-2-positive cells with disease progression and after treatment $(P<.0001)$. (B) Representative spleen cells from WT FVB/N, single and double MRP8[NRASD12/ $\mathrm{hBCL}-2] \mathrm{AML}$ transgenic mice assessed for total RAS and total BCL-2 expression by western blot analysis. Active RAS-GTP levels were measured via a sensitive RAF1-RBD pull down assay followed by western blot analysis with an anti-RAS antibody. Blots were reprobed with anti $\beta$-actin antibody to assess protein loading $(\mathrm{n}=3)$. (C) Double MRP8[NRASD12/hBCL-2] AML untreated (day 0 ) and treated (+ABT-737) mice assayed (postday 33). Mice were assessed, as in (B). Histograms of RAS-GTP and hBCL-2 normalized to actin show an increase of the hBCL-2:RAS-GTP complex. The relative values were presented as fold increase over control samples as indicated (error bar $=S D ; n=3$ ). (D) Western blot analysis showing threonine 56 and serine 70 phosphorylations of hBCL-2 of spleen cells from untreated (day 0 ) and treated (postday 33), with $\beta$-actin showing equal protein loading ( $n=2$ mice). ( $E$ ) MMP measurements by $\mathrm{DiOC}_{2}(3)$ show a reduction of dye uptake in ABT-737-treated WT and AML mice relative to untreated samples (minimum in each group, $\mathrm{n}=3$ mice). (F) Confocal microscopy of stained cells of BM showing subcellular localization of RAS:BCL-2 complex from the AML mice shifting from mitochondrial localization (Mito, stained with $\mathrm{Tom}_{2} \mathrm{O}^{+}$antibody) in untreated $(-)$ mice to plasma membrane (PM) localization (wheat germ agglutinin (WGA) after treatment $(+)$ on postday 33. Rows 1 and 2 show pretreatment BM samples with RAS and BCL-2 co-localizing with the mitochondria (pale), whereas the pink coloration with the WGA antibody is consistent with co-localizations of RAS and BCL-2 with virtually no plasma membrane staining; rows 3 and 4 are 2 independent mice posttreatment probed with either Tom 20 (rows $3 a$ and $3 b$ ) or WGA (rows $4 a$ and $4 b$ ) showing the RAS:BCL-2 complex localizing in the plasma membrane with a white color, whereas with the mitochondrial antibody, green patches are visible with pale pink coloration in row 3a consistent with RAS and BCL-2 co-localizing in the absence of mitochondrial staining (in each group, $\mathrm{n}=2$ mice).

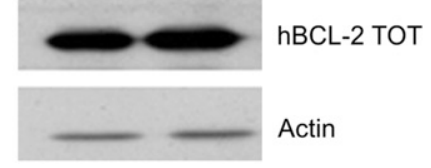

irradiated syngeneic mice showed that recipients with untreated AML cells died in 4.5 weeks, whereas those transplanted with treated cells remained alive for 11 to 11.5 weeks after which they were euthanized based on veterinary advice, as they were ill (Figure 2D) $(P<.005)$. All the engrafted mice demonstrated hBCL-2 expression measured by flow cytometry (data not shown). As we had previously reported, AML mice have an increased myeloid immature LSK cell population in the BM. After 33 days of ABT-737 treatment, the proportion of BM LSK cell population decreased to nearly normal $(12.9 \pm 1.4 \%$ untreated vs $6.4 \pm 1.1 \%$ treated $(P<.01)$ and treated vs $1.8 \pm 0.3 \%$ WT $(P \sim .1)$ (Figure $2 \mathrm{E})$, with a complete restoration of colony growth to normal range (79.6 \pm 7.0 untreated vs $48.6 \pm 13.5$ treated colony-forming unit-granulocyte macrophage progenitors per dish $(P<.01)$, in which expected normal values are $40.8 \pm 2.9(P \sim .3$ compared with treated group) (Figure 2F). 
Figure 4. (Continued).

$\mathbf{F}$
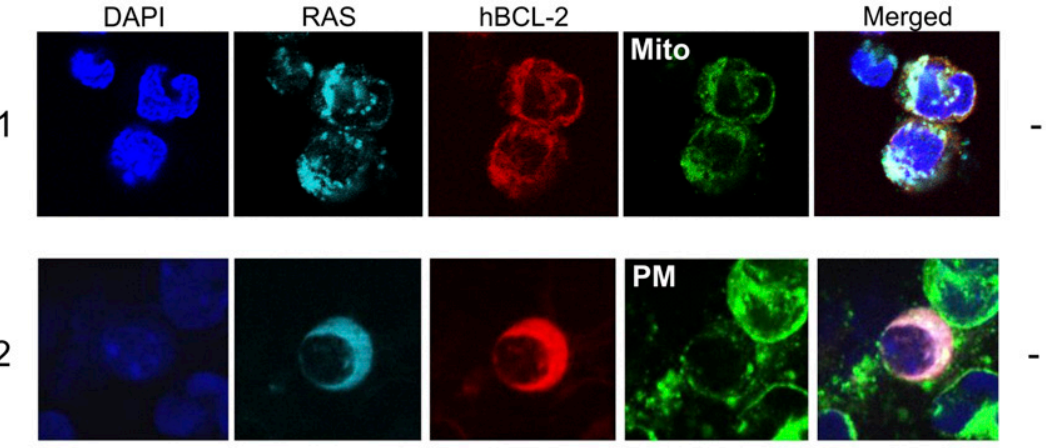

$3 a$
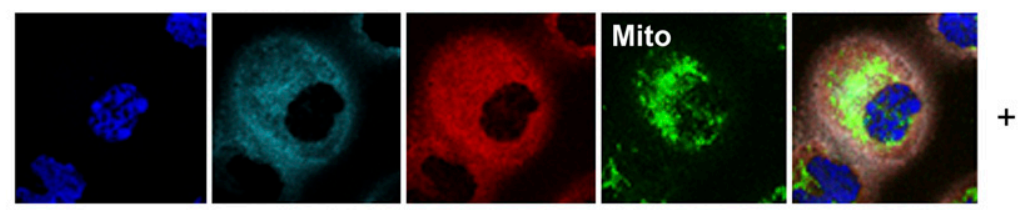

$3 b$
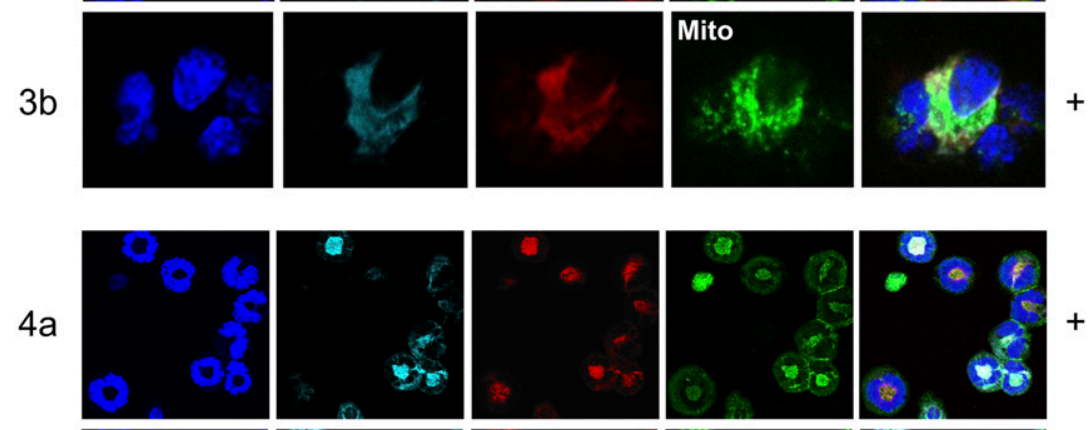

$4 \mathrm{~b}$
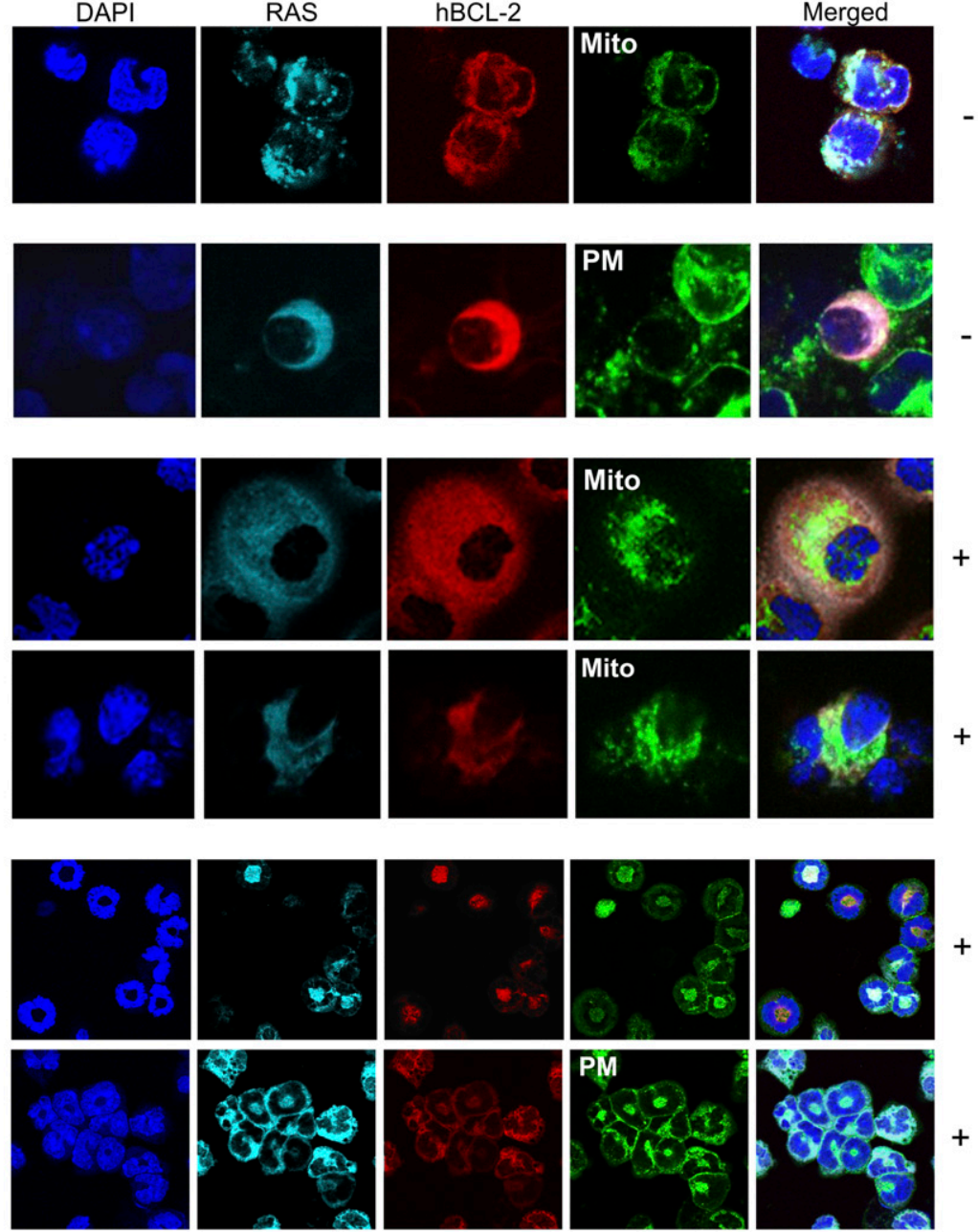

\section{ABT-737 treatment induces apoptosis and inhibition of cell proliferation}

Transformation of MDS to AML in patients is linked to a reduction of apoptosis and increased expression of BCL-2. ${ }^{6}$ Likewise, in the AML transgenic mouse overexpression of BCL-2 results in decreased apoptosis in the liver and in early apoptosis in the spleen. ${ }^{3}$ To be able to document the mechanism of blast clearance during ABT737 treatment, the apoptosis status of the infiltrated tissues was measured. Spleen cells of ABT-737-treated mice showed a decrease in annexin $\mathrm{V}^{+}$from $40.0 \pm 7.7 \%$ in the WT mice, $35.9 \pm 10.3 \%$ in the untreated AML to $4.6 \pm 2.4 \%$ cells being annexinV ${ }^{+} / 7 \mathrm{AAD}^{-}$after 23 to 25 days of treatment (ie, after 10 to 11 injections) and an increased trend toward late apoptosis at treatment $(49.2 \pm 4.9 \%$ untreated vs $59.5 \pm 14.4 \%$ treated) (Figure $3 \mathrm{~A}$ ). No significant differences in apoptosis was observed between the WT untreated and treated mice (early $P \sim .08$; late apoptosis $P \sim .21$ ). Liver and spleen were studied by single photon emission computed tomography (SPECT); at days 23 to 25 , analyses of paired pretreated and posttreated WT and AML mice were imaged (Figure 3B; supplemental Figure 3). Untreated and treated mice show that in AML mice, ABT-737 treatment induces a more than twofold increase of the radioactive ${ }^{99 \mathrm{~m}} \mathrm{Tc}$ annexinV uptake in the liver and spleen area (Figure 3B). Imaging of WT mice showed no increase in uptake of radioactivity post treatment compared with pretreatment profiles (Figure 3B; supplemental Figure 3). This result was corroborated by an increased apoptosis in the treated AML mice assayed by the TUNEL of liver sections (Figure 3C); the nuclei of the hepatocytes are stained clearly in blue, and the brown staining apoptotic invading hematopoietic cells are in the sinusoid spaces. An increased caspase 3-dependent cleavage was detected (Figure 3D). BCL-X, a known target of ABT- $737^{11}$ is downregulated in spleen cells of ABT-737 AML mice while MCL-1, a protein known to be linked to ABT-737 resistance, ${ }^{12}$ is unaffected by the treatment (Figure $3 \mathrm{E}$ ).

Then the control on cell growth by ABT-737 treatment was analyzed. Cyclin D1, which is maximally expressed in mid-to-late G1 phase, was found to be markedly decreased with treatment in both the Mac- $1^{+}$and Sca- ${ }^{+}$compartments. This data are consistent with the proliferative capacity of AML leukemic cells and that of mutant RAS-mediated myelopoiesis, ${ }^{3}$ as well as the previously reported anti-proliferative property of ABT-737..$^{31}$ The increased myelopoiesis is not reflected in the expression of the alternative target of ABT-737, BCL-xL, which is only marginally downregulated with treatment in the Mac-1 and Sca-1 compartments, consistent with the previously reported high expression levels of MCL-1mediating resistance. ${ }^{11}$ Phosphorylated p38-MAPK was significantly upregulated after treatment. p2 $1^{\text {Waf1/Cip } 1}$ expression is stable, as previously observed in the MRP8NRASD12 mouse models, through 
a cyclin D1 imposed block. ${ }^{32}$ Likewise, cyclin D3 and cyclindependent kinase inhibitors ( $\mathrm{p} 15^{\mathrm{INK} 4 \mathrm{~B}}$ and $\mathrm{p} 27^{\mathrm{kip} 1}$ ) were not significantly modified (Figure 3E). The marginal decrease in the level of $\mathrm{p} 27^{\mathrm{kip} 1}$ in the Mac-1 and Sca-1 compartments of treated animals is indicative of a release of the G1-arrest, whereas no such change was observed in the S-phase entry $\mathrm{p} 15^{\mathrm{INK} 4 \mathrm{~B}}$ protein or the $\mathrm{pRb}$ tumor suppressor (data not shown).

\section{Localization of the RAS:BCL-2 complex to the plasma membrane and dephosphorylation of RAS signaling proteins in AML mice by reducing the MMP}

BCL-2 expression was increased with disease progression from single to double transgenic mice (Figure 4A); we have previously reported that this may be due to the expansion of the Sca- $1^{+}$ compartment. ${ }^{3}$ ABT-737 treatment increased the percentage of cells expressing BCL-2 in the peripheral blood (Figure 4A). Similarly, RAS and BCL-2 expression measured by western blot analysis also revealed an increase of both transgenes with disease progression, as we previously described (Figure 4B). ${ }^{3}$ We compared RAS activity and co-localization of hBCL-2 in the NRAS:BCL-2 complex in ABT-737-treated mice compared with untreated mice using RASGTP pull down assays and confocal microscopy. Normalized levels of activated RAS-GTP are increased after treatment (Figure 4C). Likewise, normalized hBCL-2 level remains in the RAS complex after treatment (Figure 4C), with no significant change in its phosphorylated status whether on serine 70 or threonine 56 (Figure 4D). It has been previously shown that ABT-737 alters the MMP ${ }^{11}$ in this present study, there is a significant increase in MMP in AML compared with WT mice $(P<.005)$. Treatment with the inhibitor significantly reduced the MMP of the WT and diseased mice (Figure 4E) $(P<.005$ and $P<.001$, respectively). No difference in total mitochondria numbers were observed between the groups measured by the cell-permeant MitoTracker probe (Invitrogen, Carlsbad, CA) (data not shown). AML transgenic mice are characterized by an NRAS:BCL-2 complex localized at the mitochondria, where BCL-2 is normally found (Figure 4F). ${ }^{3}$ However, after ABT-737 treatment, the localization of the NRAS: BCL-2 complex shifts to the plasma membrane (Figure 4F). These results indicate that despite the clinical and apoptotic effect, ABT737 is not capable of disrupting the NRAS:BCL-2 complex (Figures 4C,F).

As RAS is found in its activated RAS-GTP form after ABT-737 treatment, we next examined whether differential patterns of RAS downstream protein phosphorylations could be identified after treatment by immunoblot and NIA. After treatment in vivo, phosphorylated ERK (pERK)1/2 and pAKT levels were highly reduced in comparison with untreated mice (Figure 5A-B). Culturing the AML spleen cells ex vivo for 24 hours showed that ABT-737 is acting directly on the leukemic cells to reduce pERK and pAKT (Figure 5C). Using the NIA, we estimated the level of different phosphorylated MEK (pMEK) isoforms; the traces of the 2 phospho-forms of the MEK1 and MEK2 isoforms are modulated during disease progression and restored to near normal levels by treatment in vivo (Figure 5D). Total MEK1 levels are found very much reduced in 2 AML mice compared with WT controls with decreased pMEK1-5 and pMEK1-6 peaks (Figure 5Di). ABT-737 treatment induced a significant trend to restore WT MEK1 levels and phosphorylation patterns (Figure 5Di). Similar results are observed with the MEK2 isoforms with the restoration of peaks MEK2-3 and MEK2 which were lost in the AML mice upon treatment. (Figure 5Dii).

\section{ABT-737 treatment induces regulation and activation of pathways implicated in cell survival, proliferation, and stem cells in treated AML mice}

ABT-737 targets members of the BCL-2 family that includes both pro-apoptotic and anti-apoptotic molecules. ${ }^{33}$ To gain further insights on the potential pathways involved, exon-specific gene expression was studied in Sca- ${ }^{+}$splenocytes in AML mice after ABT-737 treatment $(n=3)$ compared with untreated mice $(n=3)$ (GEO accession no. GSE48601). The analysis revealed 997 differentially expressed genes, distributed in 2 distinct cluster groups (Figure 6). The full gene list represents 764 upregulated and 233 downregulated genes (supplemental Table 1). Validation was carried out in 3 representative genes by real-time quantitative- polymerase chain reaction (data not shown). Downregulation of anti-apoptotic genes, such as BCL-2a1b (Figure 6; supplemental Table 1), or upregulation of pro-apoptotic genes, such as PARP4, CALPAIN2, TNFR, and CARD, was highly significant (Figure 6; Table 1). Restoration of normal hematopoiesis was confirmed by the upregulation of myeloid differentiation genes (CD14, CSF1, RARa) and downregulation of genes implicated in cell proliferation (Hsp60, MYC and E2F1) (Figure 6; Table 1). Pathway analyses of the gene expression profiles revealed combined modulations in pathways implicated in cell cycle and genomic instability, together with genes involved in proliferation and myeloid differentiation. ${ }^{34}$ Treatment upregulated the expression of the gene coding for TGFRIII, a tumor suppressor gene, due to its direct effects on regulating cell migration, invasion, proliferation, and angiogenesis. ${ }^{34}$ When compared with the MRP8NRASD12 mouse, the genes modulated by ABT-737 treatment correspond to AML progression genes including thrombospondin 1 (known as a tumor suppressor gene and are upregulated in RAS and AML ABT-737treated mice), thus corroborating the efficacy of ABT-737 on the leukemic clone. Stem cell-related genes TCF7L2 (or TCF4), PIWII2, BRMPR1a, and Spp1, which are important for development, maintenance, and differentiation, are upregulated with treatment.

\section{Discussion}

ABT-737 shows biological efficacy in this mouse model of AML; the difference in survival between the untreated and treated groups is highly significant in mice that had the treatment completed. The mice clearly gain weight with treatment. The blood counts show that the platelets and lymphocytes are not rescued due to the reported toxicity of the drug as it targets BCL-xL. ${ }^{30,35}$ However, the other blood parameters, such as neutrophil count and white blood cell counts are rescued. BM blasts are significantly reduced, and the organ invasion is reduced, consistent with the increase of differentiated cells illustrated by the increase in $\mathrm{Mac}-1^{\mathrm{hi}} / \mathrm{Gr}-1^{\mathrm{lo}}$ populations (data not shown) and the diminution of the expanded LSK compartment and the late (colony-forming unit) progenitors, thereby indicative of targeting the primitive leukemic cells. The finding that genes important for stem cell development, maintenance, and differentiation are regulated after treatment may reflect the partial restoration of normal stem cell function, as evidenced by the increased survival of mice transplanted with cells from the AML-treated group. Interestingly, the upregulation of Spp1 is compatible with previous reports of its effect on dampening hematopoietic stem cell/progenitor proliferative capacity within the $\mathrm{BM}$ microenvironment, ${ }^{36}$ as well as the raised levels of its gene product (osteopontin) in the serum of leukemia patients as compared with normal controls, ${ }^{37}$ with its transcriptional regulation via a RAS-mediated 

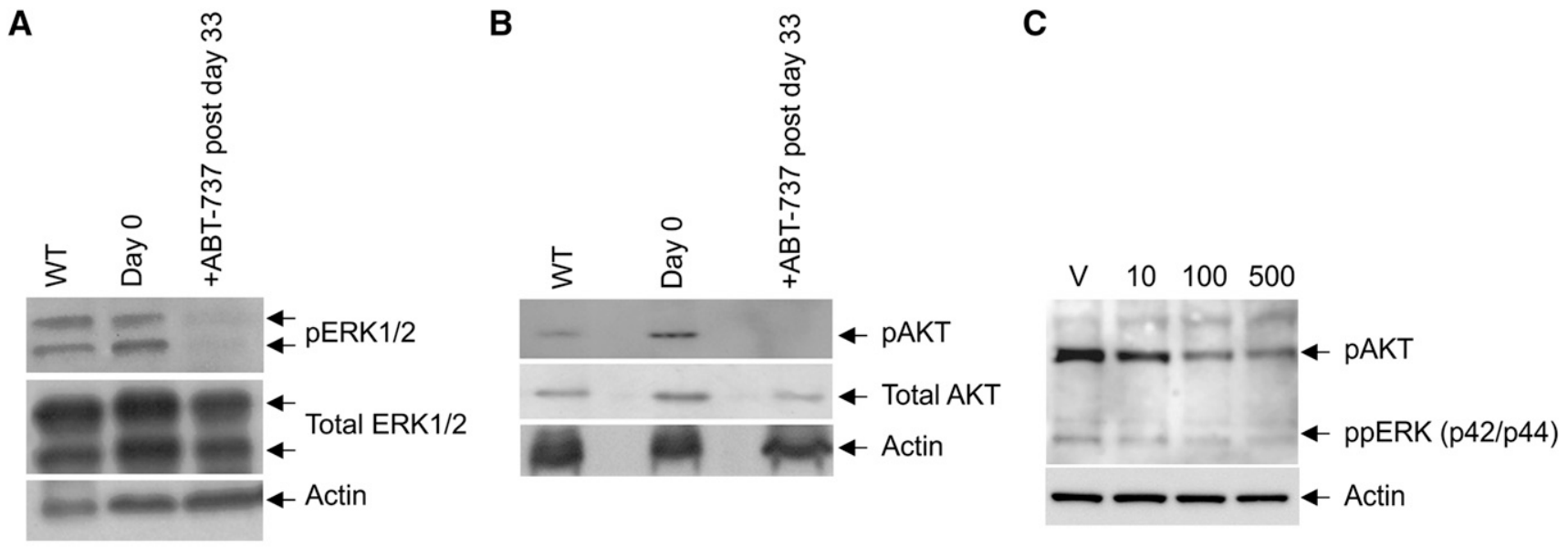

D i
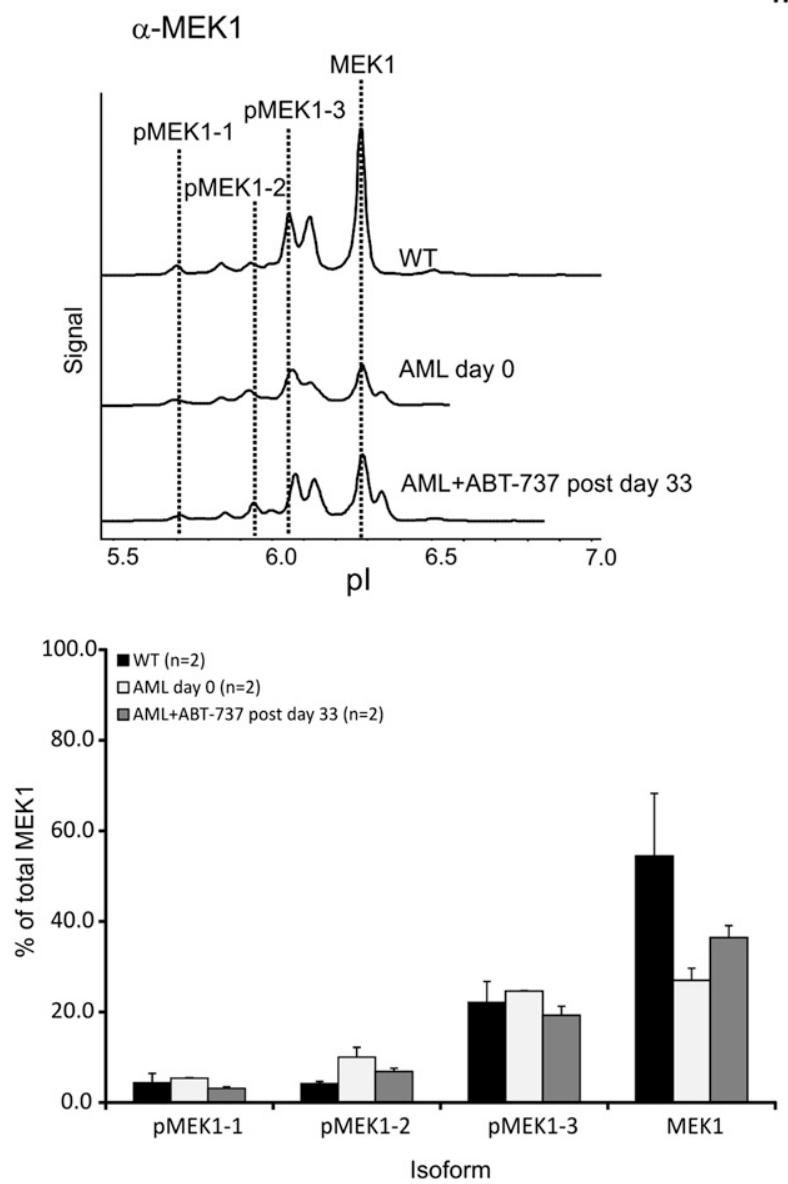

ii $\alpha-M E K 2$
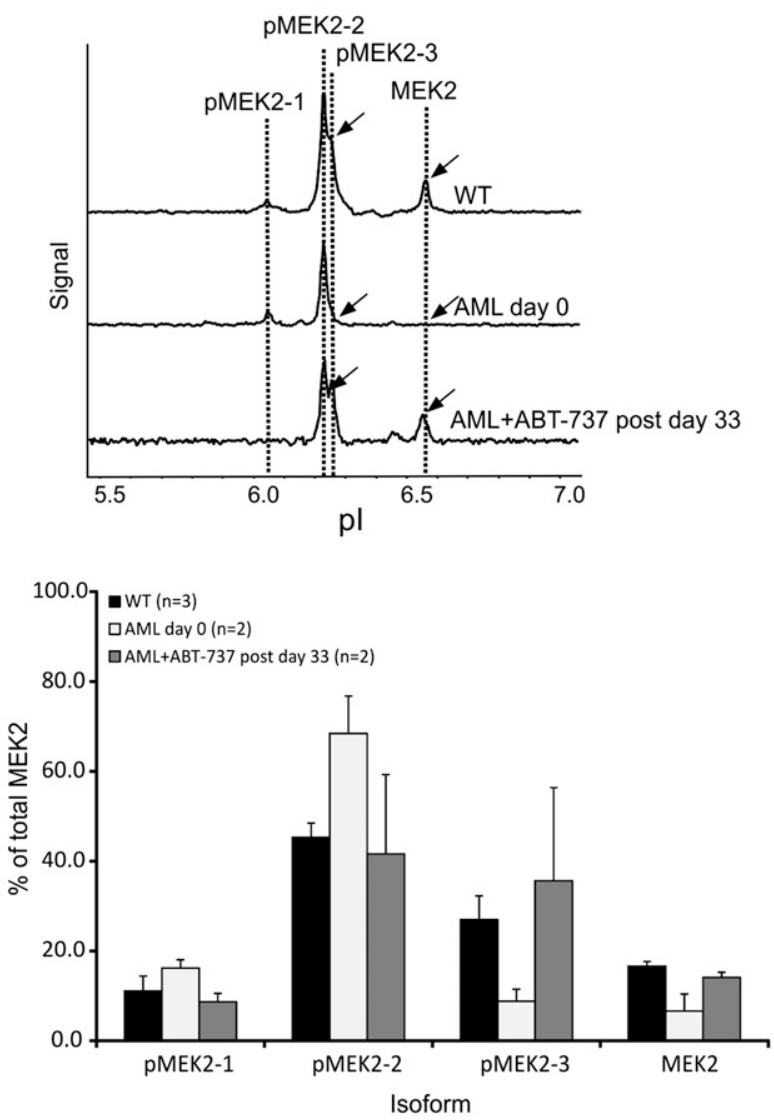

Figure 5. Modification of signaling proteins after treatment. Western blot analysis showing dephosphorylation of proteins from spleen cells of (A) ERK1/2 and (B) AKT on day 0 and after ABT-737 treatment (postday 33), and normalized protein loading confirmed by probing for- $\beta$-actin $(n=2$ mice). (C) Representative western blot analysis showing dephosphorylation of proteins of ppERK and pAKT of spleen cells after culturing (in triplicate) in vitro with vehicle (V), 10, 100, or 500 nM ABT-737 for 24 hours ( $n=2$ mice). (D) Nanoimmunoassay using the NanoPro (ProteinSimple) isoelectric focusing for detection of MEK signatures. Representative trace of spleen cells of WT FVB/N and AML untreated mice (day 0) and after ABT-737 treatment (postday 33) showing the dephosphorylated isoform pMEK2-3 and restoration of MEK2 expression (arrowed); histogram showing restoration of normal FVB/N signatures of the different isoforms after treatment. Each reaction was done in triplicate. Representative of at least 2 mice $(\mathrm{n}=2)$ in each group.

signaling pathway. ${ }^{38}$ In this context, Spp1 may be influencing the proliferation of leukemia initiating cells by reducing their proliferative capacity and restoring the stem cells to their normal phenotype.

Treatment with ABT-737 induces apoptosis of myeloid blasts that invade organs, as measured by annexinV/7AAD flow cytometry, SPECT, and TUNEL, consistent with clearance of the disease, as observed by the reduction in BM blasts. The hepatocytes are clearly morphologically intact and therefore ABT-737 does not appear to be toxic to these cells, and the apoptosis induced appear to be targeting the infiltrating myeloid cells. The apoptosis profiles by flow and SPECT confirm the specificity of the ABT-737 for BCL2-expressing cells and cell death is not due to liver toxicity. This shows there is differential targeting of diseased BCL-2-expressing cells sparing the normal cells. The upregulation of pro-apoptotic 


\section{Sca1+ Spleen cells}

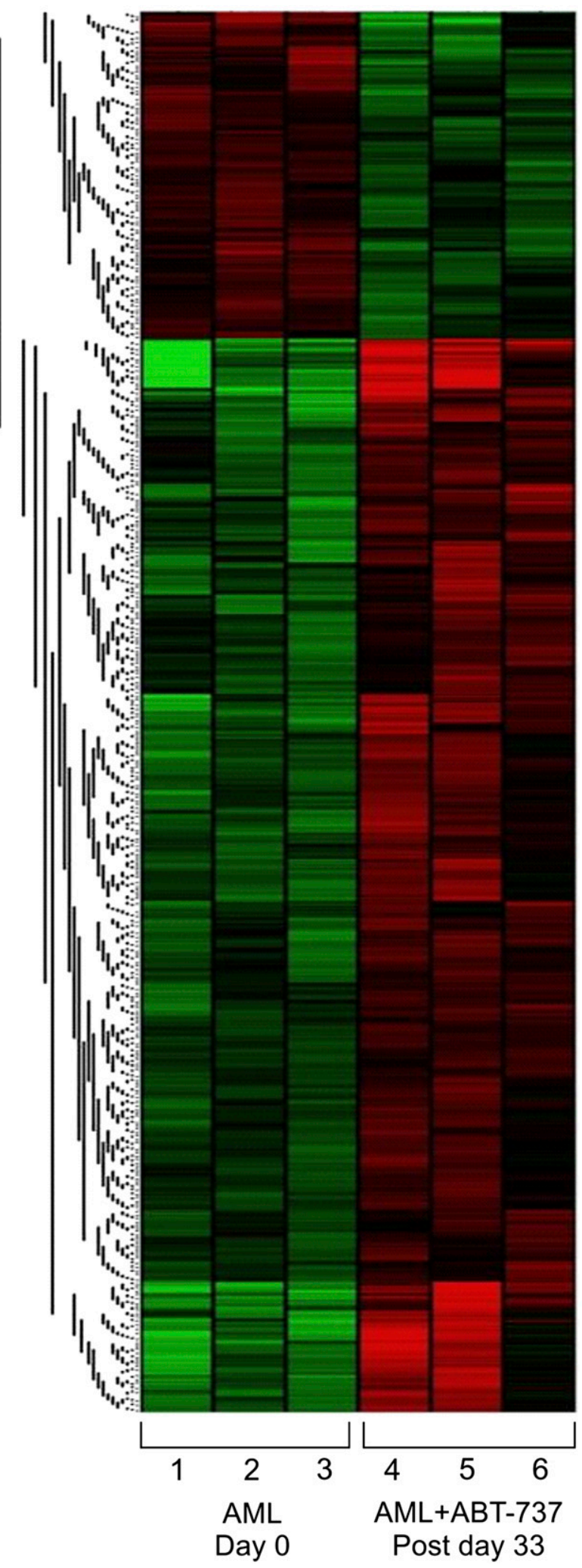

Figure 6. ABT-737 treatment-induced differential regulation and activation of pathways implicated in cell survival and proliferation assayed by gene expression profiling. Exon specific microarray heat maps of Sca- $1^{+}$purified spleen cells from untreated (day 0 ) and ABT-737 treated (postday 33 ) of AML mice relative to WT FVB/N. Each row (1-6) represents an independent mouse $(n=3)$ in each group (GEO accession no. GSE48601). genes were observed in gene expression profiles. Interestingly, among the downregulated genes, we found the anti-apoptotic Bcl$2 \mathrm{alb}$ gene that encodes the protein Alb implicated in the resistance to ABT-737. ${ }^{39}$ These data are consistent with the reduced phosphorylation of anti-apoptotic AKT, which normally inhibits pro-apoptotic BCL-2 associated death promoter protein BAD, which in turn inhibits anti-apoptotic BCL-2; dephosphorylation of AKT results in the dominance of pro-apoptotic features. AKT also induces mammalian target of rapamycin, which in turn activates p70S6K, which is anti-apoptotic. Therefore, the downregulation of this pathway by dephosphorylation of AKT results in increased apoptosis, as we have observed; nevertheless, this efficacy does not lead to complete remission, although hematopoiesis returns to an MDS phenotype with reduced BM blasts and increased dysplasia. The relatively increased MMP of AML as compared with WT splenocytes is consistent with increased levels of reactive oxygen species, as previously reported in these mice. ${ }^{40}$

The RAS:BCL-2 complex is not disrupted by treatment, which is to be expected, as the binding site of RAS to BCL-2 is the BH4 domain, ${ }^{41}$ whereas ABT-737 binds the BCL-2 homology domain 3 domain. The localization of the RAS:BCL-2 complex shifts from the mitochondria where BCL-2 is localized ${ }^{3}$ to the plasma membrane reminiscent of the localization of the single NRASD12 transgenic mice and consistent with increased apoptosis. ${ }^{3,10}$ Thus, presumably due to the reduction in MMP induced by ABT-737, downstream of RAS, dephosphorylation of AKT, ERK, and MEK are more likely to reflect the return to a more normalized hematopoiesis, albeit with remaining MDS features. Although high levels of MCL-1 are critical for survival of AML cells, ${ }^{42}$ increased expression of MCL-1 is also thought to confer resistance to ABT-737, as the drug binds poorly to this protein. ${ }^{11,12,43}$ ERK promotes MCL-1 expression by ELK $1^{44}$ and stabilizes the protein by phosphorylation within the proline/glutamic acid/serine/threonine site ${ }^{45}$; therefore, its dephosphorylation in our mouse model post-ABT-737 treatment is consistent with the absence of increased expression of MCL-1 and the sensitivity of the AML mice to this reagent. It has been shown that MEK inhibition enhances ABT-737-induced leukemia cell apoptosis by preventing ERK-mediated MCL-1 induction ${ }^{46}$; in our mouse model, the MEK signatures are restored to nearly WT levels observed in normal mice, which again is consistent with sensitivity of the mice to this treatment. These patterns are likely to be a consequence of the restoration of normal hematopoiesis, although our ex vivo data indicates a direct effect of ABT-737 on the abnormal cells with reduced phosphorylation of RAS signaling proteins, ERK and AKT. The cells after the course of treatment in vivo are most likely a mixture of abnormal and normal cells, as evidenced by the reconstitution of longer-lived mice in the secondary transplants of treated cells and the subsequent delayed development of disease.

The rescue from lethality with ABT-737 was associated with a concomitant suppression of cyclin D1/p2 $7^{\text {Kip1 }}$ S-phase-associated proteins. These findings are wholly consistent with the reduced clonogenic capacity of treated cells and with the G1/S checkpoint commonly compromised in many tumor cells. These mechanisms allow the repair of DNA damage due to genetic instability, as reported in AML patient cells ${ }^{47}$ and in this AML model ${ }^{40}$ Furthermore, ABT-737 was found to profoundly induce stress signals as illustrated by upregulation of phospho-p38 $8^{\mathrm{MAPK}}$ in both Sca-1 and Mac-1 compartments; hence, concomitant signals emanating via this pathway may represent a viable target in AML. These data indicate that NRASD12 and BCL-2 cooperate in vivo via tightly regulated cell cycle cyclins and inhibitors consistent with the proliferative capacity 
of hematopoietic cells during AML disease expansion, which is in turn is modulated by ABT-737.

As with other reported studies, with ABT-737, the other targets of the molecule are not completely elucidated in vitro. The increase of BCL-2 expression at the end of treatment may be due to the increased proliferation of the mature myeloid cells that harbor the BCL-2 transgene; this hypothesis is supported by the upregulation of the myeloid differentiation genes observed in the arrays. The short duration of treatment may not have allowed complete terminal differentiation and recovery of normal hematopoiesis, and because this is a transgenic model, complete and durable normal hematopoiesis can never be restored, and the mice inevitably relapse and die of disease. Furthermore, careful cytological analysis of the BM and peripheral blood documented the persistence of granulocytes with dysplasia.

In summary ABT-737 was found to be of benefit in this mouse model of AML, targeting leukemia initiating cells, LSK cells, and progenitors, and inducing upregulation of differentiation, and downregulation of cell cycle and proliferation genes, characteristic of the NRASD12 MDS mouse with a shift in NRAS:BCL-2 localization and protein modification signatures toward a normal phenotype. These measured changes translate to a significantly prolonged lifespan that supports the notion that clinical trials may be warranted in AML patients with this class of inhibitor or its BCL-2-specific derivative, ABT-199, which has recently been developed. ${ }^{48,49}$

\section{Acknowledgments}

The authors thank Annie Soulie and Murielle Reboul for their technical assistance with confocal microscopy and tissue preparation in the early stages of the project, members of the Institut Universitaire d'Hématologie specifically the Département d'Expérimentation Animale, Bernard Boursin and Elisabeth Savariau from the photography laboratory, the Imagery Department for confocal microscopy (who are supported by grants from the Conseil Régional d'Ile-deFrance and the Ministère de la Recherche), and Michael Bishop and Scott Kogan (University of California, San Francisco) for the MRP8NRASD12, Irving Weissman and Eric Lagasse (Stanford University) for the MRP8BCL-2 mice and William G. Bornmann (MD Anderson Cancer Center) for generously providing ABT-737 in the early part of the study and Abbott for generously providing ABT-737 to enable us to complete this study.

This work was supported by grants from Fondation de France, Fondation ARC pour la Recherche sur le Cancer, Association Laurette Fugain, Ligue Contre le Cancer, Institut National de la Santé et de la Recherche Médicale, Leukaemia \& Lymphoma Research (United Kingdom), and the National Institutes of Health: National Cancer Institute (K23CA140722) (A.C.F. and D.W.F.).

R.A.P. and C.C. are members of the European Cooperation in Science and Technology Action BM0801 and the European Leukemia Network. S.B. and C.L.P. are recipients of the European Cooperation in Science and Technology Action BM0801 short-term scientific mission awards.

\section{Authorship}

Contribution: S.B., N.O., R.A.P., A.W., M.K., M.A., A.C.F., D.W.F., P.F., and C.C. designed experiments; S.B., N.O., R.A.P., and C.C. wrote the manuscript; S.B., N.O., R.A.P., P.K., P.G., C.L.P., N.S., P.d.l.G., C.L., A.J., M.-E.N., F.H., L.S.-M., A.W.T., and M.P. performed experiments; S.B., N.O., R.A.P., P.K., P.G., C.L.P., N.S., P.d.l.G., C.L. A.J., M.-E.N., F.H., L.S.-M., A.W.T., M.P., R.W., and C.C. analyzed the data; A.W., M.K., and M.A. provided reagents; and all of the authors edited the manuscript.

Conflict-of-interest disclosure: P.d.l.G. is a salaried employee of Genosplice. A.T. is a salaried employee of Protein Simple. D.W.F. and A.C.F. have patents pending through Stanford University relating to the nanoimmunoassay technology. The remaining authors declare no competing financial interests.

Correspondence: Rose Ann Padua, UMRS-940, Institut Universitaire d'Hematologie, F-75475 Paris, France; e-mail: rose-ann.padua@ inserm.fr.

\section{References}

1. Padua RA, Guinn BA, Al-Sabah Al, et al. RAS, FMS and p53 mutations and poor clinical outcome in myelodysplasias: a 10-year follow-up. Leukemia. 1998;12(6):887-892.

2. Kogan SC, Lagasse E, Atwater S, et al. The PEBP2betaMYH11 fusion created by $\operatorname{lnv}(16)$ (p13;q22) in myeloid leukemia impairs neutrophil maturation and contributes to granulocytic dysplasia. Proc Natl Acad Sci USA. 1998;95(20): 11863-11868.

3. Omidvar N, Kogan S, Beurlet S, et al. BCL-2 and mutant NRAS interact physically and functionally in a mouse model of progressive myelodysplasia. Cancer Res. 2007;67(24):11657-11667.

4. Lagasse E, Weissman IL. bcl-2 inhibits apoptosis of neutrophils but not their engulfment by macrophages. J Exp Med. 1994;179(3): 1047-1052.

5. Parker JE, Mufti GJ. The myelodysplastic syndromes: a matter of life or death. Acta Haematol. 2004;111(1-2):78-99.

6. Parker JE, Mufti GJ, Rasool F, et al. The role of apoptosis, proliferation, and the $\mathrm{Bcl}$-2-related proteins in the myelodysplastic syndromes and acute myeloid leukemia secondary to MDS. Blood. 2000;96(12):3932-3938.
7. Parker JE, Fishlock KL, Mijovic A, et al. 'Low-risk' myelodysplastic syndrome is associated with excessive apoptosis and an increased ratio of pro- versus anti-apoptotic bcl-2-related proteins. Br J Haematol. 1998;103(4):1075-1082.

8. Karakas T, Miething CC, Maurer U, et al. The coexpression of the apoptosis-related genes bcl-2 and wt1 in predicting survival in adult acute myeloid leukemia. Leukemia. 2002;16(5): 846-854.

9. Karakas T, Maurer U, Weidmann E, et al. High expression of bcl-2 mRNA as a determinant of poor prognosis in acute myeloid leukemia. Ann Oncol. 1998;9(2):159-165.

10. Le Pogam $C$, Krief $P$, Beurlet $S$, et al. Localization of the NRAS:BCL-2 complex determines antiapoptotic features associated with progressive disease in myelodysplastic syndromes. Leuk Res. 2012;37(3):312-319.

11. Konopleva M, Contractor R, Tsao T, et al. Mechanisms of apoptosis sensitivity and resistance to the $\mathrm{BH} 3$ mimetic $\mathrm{ABT}-737$ in acute myeloid leukemia. Cancer Cell. 2006;10(5): 375-388.

12. van Delft MF, Wei $A H$, Mason $K D$, et al. The $B H 3$ mimetic ABT-737 targets selective $\mathrm{Bcl}-2$ proteins and efficiently induces apoptosis via Bak/Bax if Mcl-1 is neutralized. Cancer Cell. 2006;10(5): 389-399.

13. Mason $\mathrm{KD}$, Vandenberg $\mathrm{CJ}$, Scott $\mathrm{CL}$, et al. In vivo efficacy of the Bcl-2 antagonist ABT-737 against aggressive Myc-driven lymphomas. Proc Natl Acad Sci USA. 2008;105(46):17961-17966.

14. Hann CL, Daniel VC, Sugar EA, et al. Therapeutic efficacy of ABT-737, a selective inhibitor of $\mathrm{BCL}-2$, in small cell lung cancer. Cancer Res. 2008;68(7):2321-2328.

15. High LM, Szymanska B, Wilczynska-Kalak U, et al. The Bcl-2 homology domain 3 mimetic ABT-737 targets the apoptotic machinery in acute lymphoblastic leukemia resulting in synergistic in vitro and in vivo interactions with established drugs. Mol Pharmacol. 2010;77:483-494.

16. Olberding KE, Wang $X$, Zhu $Y$, et al. Actinomycin $D$ synergistically enhances the efficacy of the $\mathrm{BH} 3$ mimetic ABT- 737 by downregulating $\mathrm{Mcl}-1$ expression. Cancer Biol Ther. 2010;10(9): 918-929.

17. Zhang $\mathrm{C}$, Cai TY, Zhu H, et al. Synergistic Antitumor Activity of Gemcitabine and ABT-737 In Vitro and In Vivo through Disrupting the 
Interaction of USP9X and Mcl-1. Mol Cancer Ther. 2011;10(7):1264-1275.

18. Miller LA, Goldstein NB, Johannes WU, et al. BH3 mimetic ABT-737 and a proteasome inhibitor synergistically kill melanomas through Noxa-dependent apoptosis. J Invest Dermatol. 2009;129(4):964-971.

19. Zhang W, Konopleva M, Ruvolo VR, et al. Sorafenib induces apoptosis of AML cells via Bim-mediated activation of the intrinsic apoptotic pathway. Leukemia. 2008;22(4):808-818.

20. Tse C, Shoemaker AR, Adickes J, et al. ABT-263: a potent and orally bioavailable Bcl-2 family inhibitor. Cancer Res. 2008;68(9):3421-3428.

21. Gandhi L, Camidge DR, Ribeiro de Oliveira M, et al. Phase I study of Navitoclax (ABT-263), a novel $\mathrm{Bcl}-2$ family inhibitor, in patients with small-cell lung cancer and other solid tumors. J Clin Oncol. 2011;29(7):909-916.

22. Hallek M, Pflug N. State of the art treatment of chronic lymphocytic leukaemia. Blood Rev. 2011; 25(1):1-9.

23. Roberts AW, Seymour JF, Brown JR, et al. Substantial susceptibility of chronic lymphocytic leukemia to BCL2 inhibition: results of a phase study of navitoclax in patients with relapsed or refractory disease. J Clin Oncol. 2011;30(5): 488-496.

24. Kogan SC, Ward JM, Anver MR, et al. Bethesda proposals for classification of nonlymphoid hematopoietic neoplasms in mice. Blood. 2002; 100(1):238-245.

25. Cabreiro F, Picot CR, Perichon M, et al. Overexpression of mitochondrial methionine sulfoxide reductase $\mathrm{B} 2$ protects leukemia cells from oxidative stress-induced cell death and protein damage. J Biol Chem. 2008;283(24): 16673-16681.

26. Novo D, Perlmutter NG, Hunt RH, et al. Accurate flow cytometric membrane potential measurement in bacteria using diethyloxacarbocyanine and a ratiometric technique. Cytometry. 1999;35(1): 55-63.

27. Fan AC, Deb-Basu D, Orban MW, et al. Nanofluidic proteomic assay for serial analysis of oncoprotein activation in clinical specimens. Nat Med. 2009;15(5):566-571.

28. de la Grange P, Dutertre M, Martin N, et al. FAST DB: a website resource for the study of the expression regulation of human gene products. Nucleic Acids Res. 2005;33(13):4276-4284.

29. de la Grange P, Gratadou L, Delord M, et al. Splicing factor and exon profiling across human tissues. Nucleic Acids Res. 2010;38(9): 2825-2838.

30. Zhang H, Nimmer PM, Tahir SK, et al. Bcl-2 family proteins are essential for platelet survival. Cell Death Differ. 2007;14(5):943-951.

31. Cencic R, Carrier M, Trnkus A, et al. Synergistic effect of inhibiting translation initiation in combination with cytotoxic agents in acute myelogenous leukemia cells. Leuk Res. 2010; 34(4):535-541.

32. Coleman ML, Marshall CJ, Olson MF. Ras promotes p21(Waf1/Cip1) protein stability via a cyclin D1-imposed block in proteasomemediated degradation. EMBO J. 2003;22(9): 2036-2046

33. Ezzoukhry Z, Louandre C, Francois C, et al. The $\mathrm{Bcl}-2$ homology domain $3(\mathrm{BH} 3)$ mimetic ABT-737 reveals the dynamic regulation of bad, a proapoptotic protein of the Bcl-2 family, by Bcl-xL. Mol Pharmacol. 2011;79(6):997-1004

34. Gatza CE, Oh SY, Blobe GC. Roles for the type III TGF-beta receptor in human cancer. Cell Signal. 2010;22(8):1163-1174.

35. Schoenwaelder SM, Jarman KE, Gardiner E, et al. Bcl-xL inhibitory BH3 mimetics can induce a transient thrombocytopathy that undermines the hemostatic function of platelets. Blood. 2011; 118(6):1663-1674.

36. Nilsson SK, Johnston HM, Whitty GA, et al. Osteopontin, a key component of the hematopoietic stem cell niche and regulator of primitive hematopoietic progenitor cells. Blood. 2005;106(4):1232-1239.

37. Flamant S, Kortulewski T, Dugray A, et al. Osteopontin is upregulated by BCR-ABL. Biochem Biophys Res Commun. 2005;333(4): 1378-1384.

38. Hickey FB, England K, Cotter TG. Bcr-Abl regulates osteopontin transcription via Ras, PI-3K, aPKC, Raf-1, and MEK. J Leukoc Biol. 2005;78(1):289-300.

39. Vogler M, Butterworth M, Majid A, et al. Concurrent up-regulation of $B C L-X L$ and BCL2A1 induces approximately 1000 -fold resistance to
ABT-737 in chronic lymphocytic leukemia. Blood. 2009;113(18):4403-4413.

40. Rassool FV, Gaymes TJ, Omidvar N, et al. Reactive oxygen species, DNA damage, and error-prone repair: a model for genomic instability with progression in myeloid leukemia? Cancer Res. 2007;67(18):8762-8771.

41. Denis GV, Yu Q, Ma P, et al. Bcl-2, via its $B H 4$ domain, blocks apoptotic signaling mediated by mitochondrial Ras. J Biol Chem. 2003;278(8): 5775-5785.

42. Glaser SP, Lee EF, Trounson E, et al. Antiapoptotic $\mathrm{Mcl}-1$ is essential for the development and sustained growth of acute myeloid leukemia Genes Dev. 2012;26(2):120-125.

43. Chen S, Dai Y, Harada $\mathrm{H}$, et al. Mcl-1 down-regulation potentiates ABT-737 lethality by cooperatively inducing Bak activation and Bax translocation. Cancer Res. 2007;67(2):782-791.

44. Townsend KJ, Zhou P, Qian L, et al. Regulation of MCL1 through a serum response factor/ Elk-1-mediated mechanism links expression of a viability-promoting member of the BCL2 family to the induction of hematopoietic cell differentiation. J Biol Chem. 1999;274(3): 1801-1813.

45. Domina AM, Vrana JA, Gregory MA, et al. MCL1 is phosphorylated in the PEST region and stabilized upon ERK activation in viable cells, and at additional sites with cytotoxic okadaic acid or taxol. Oncogene. 2004;23(31): 5301-5315.

46. Konopleva M, Milella M, Ruvolo $\mathrm{P}$, et al. MEK inhibition enhances ABT-737-induced leukemia cell apoptosis via prevention of ERK-activated MCL-1 induction and modulation of MCL-1/BIM complex. Leukemia. 2012;26(4):778-787.

47. Suela J, Alvarez S, Cigudosa JC. DNA profiling by arrayCGH in acute myeloid leukemia and myelodysplastic syndromes. Cytogenet Genome Res. 2007;118(2-4):304-309.

48. Souers AJ, Leverson JD, Boghaert ER, et al. ABT-199, a potent and selective BCL-2 inhibitor, achieves antitumor activity while sparing platelets. Nat Med. 2013;19(2):202-208.

49. Davids MS, Letai A. ABT-199: taking dead aim at BCL-2. Cancer Cell. 2013;23(2):139-141. 


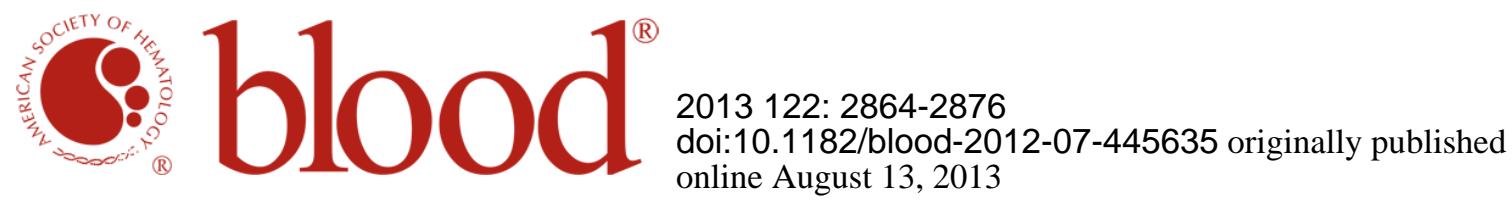

\section{BCL-2 inhibition with ABT-737 prolongs survival in an NRAS/BCL-2 mouse model of AML by targeting primitive LSK and progenitor cells}

Stephanie Beurlet, Nader Omidvar, Petra Gorombei, Patricia Krief, Carole Le Pogam, Niclas Setterblad, Pierre de la Grange, Christophe Leboeuf, Anne Janin, Maria-Elena Noguera, Florence Hervatin, Laure Sarda-Mantel, Marina Konopleva, Michael Andreeff, Andrea W. Tu, Alice C. Fan, Dean W. Felsher, Anthony Whetton, Marika Pla, Robert West, Pierre Fenaux, Christine Chomienne and Rose Ann Padua

Updated information and services can be found at: http://www.bloodjournal.org/content/122/16/2864.full.html

Articles on similar topics can be found in the following Blood collections Myeloid Neoplasia (1588 articles)

Information about reproducing this article in parts or in its entirety may be found online at: http://www.bloodjournal.org/site/misc/rights.xhtml\#repub_requests

Information about ordering reprints may be found online at:

http://www.bloodjournal.org/site/misc/rights.xhtml\#reprints

Information about subscriptions and ASH membership may be found online at: http://www.bloodjournal.org/site/subscriptions/index.xhtml 